\title{
Arabidopsis EGY1 Is Critical for Chloroplast Development in Leaf Epidermal Guard Cells
}

\author{
Alvin Sanjaya ${ }^{1,+}{ }^{\dagger}$, Ryohsuke Muramatsu ${ }^{1,+}$, Shiho Sato $^{1}$, Mao Suzuki ${ }^{1}$, Shun Sasaki ${ }^{1}$, Hiroki Ishikawa ${ }^{1}$, \\ Yuki Fujii ${ }^{1}$, Makoto Asano ${ }^{1}$, Ryuuichi D. Itoh ${ }^{2}$, Kengo Kanamaru ${ }^{3}$, Sumie Ohbu ${ }^{4}$, Tomoko Abe ${ }^{4}$, \\ Yusuke Kazama ${ }^{4,5}$ and Makoto T. Fujiwara ${ }^{1,4, *(\mathbb{D})}$
}

1 Department of Materials and Life Sciences, Faculty of Science and Technology, Sophia University, Kioicho, Chiyoda, Tokyo 102-8554, Japan; alvin_sanjaya@protonmail.com (A.S.); ryohsuke67@outlook.com (R.M.); shiho.sato.0815@gmail.com (S.S.); m.suzuki343@gmail.com (M.S.); s.03ch.s@gmail.com (S.S.);

hiroki.0831.i@gmail.com (H.I.); y-fujii-5x8@eagle.sophia.ac.jp (Y.F.); m-asano-0h1@eagle.sophia.ac.jp (M.A.)

2 Department of Chemistry, Biology and Marine Science, Faculty of Science, University of the Ryukyus, Okinawa 903-0213, Japan; ryuitoh@sci.u-ryukyu.ac.jp

3 Faculty of Agriculture, Kobe University, Nada, Kobe 657-8501, Japan; kng@kobe-u.ac.jp

4 RIKEN Nishina Center, Wako, Saitama 351-0198, Japan; ohbu@riken.jp (S.O.); tomoabe@riken.jp (T.A.); ykaze@fpu.ac.jp (Y.K.)

5 Faculty of Bioscience and Biotechnology, Fukui Prefectural University, Eiheiji, Fukui 910-1195, Japan

* Correspondence: mtf1@mac.com; Tel.: +81-3-3238-3495

+ These authors contributed equally to this work.

\section{check for} updates

Citation: Sanjaya, A.; Muramatsu, R.; Sato, S.; Suzuki, M.; Sasaki, S.;

Ishikawa, H.; Fujii, Y.; Asano, M.; Itoh, R.D.; Kanamaru, K.; et al. Arabidopsis EGY1 Is Critical for Chloroplast Development in Leaf Epidermal Guard Cells. Plants 2021, 10, 1254. https://doi.org/10.3390/ plants10061254

Academic Editor:

Mitsumasa Hanaoka

Received: 6 May 2021

Accepted: 17 June 2021

Published: 21 June 2021

Publisher's Note: MDPI stays neutral with regard to jurisdictional claims in published maps and institutional affiliations.

Copyright: (c) 2021 by the authors. Licensee MDPI, Basel, Switzerland. This article is an open access article distributed under the terms and conditions of the Creative Commons Attribution (CC BY) license (https:/ / creativecommons.org/licenses/by/ $4.0 /)$.
Abstract: In Arabidopsis thaliana, the Ethylene-dependent Gravitropism-deficient and $\underline{Y}$ ellow-green $\underline{1}$ (EGY1) gene encodes a thylakoid membrane-localized protease involved in chloroplast development in leaf mesophyll cells. Recently, EGY1 was also found to be crucial for the maintenance of grana in mesophyll chloroplasts. To further explore the function of EGY1 in leaf tissues, we examined the phenotype of chloroplasts in the leaf epidermal guard cells and pavement cells of two ${ }^{40} \mathrm{Ar}^{17+}$ irradiation-derived mutants, Ar50-33-pg1 and egy1-4. Fluorescence microscopy revealed that fully expanded leaves of both egy1 mutants showed severe chlorophyll deficiency in both epidermal cell types. Guard cells in the egy1 mutant exhibited permanent defects in chloroplast formation during leaf expansion. Labeling of plastids with CaMV35S or Protodermal Factor1 (PDF1) promoter-driven stroma-targeted fluorescent proteins revealed that egy1 guard cells contained the normal number of plastids, but with moderately reduced size, compared with wild-type guard cells. Transmission electron microscopy further revealed that the development of thylakoids was impaired in the plastids of egy1 mutant guard mother cells, guard cells, and pavement cells. Collectively, these observations demonstrate that EGY1 is involved in chloroplast formation in the leaf epidermis and is particularly critical for chloroplast differentiation in guard cells.

Keywords: Arabidopsis thaliana; At5g35220; epidermal plastid; guard cell; pavement cell; thylakoid

\section{Introduction}

Chloroplasts are semi-autonomous double-membrane-bound organelles containing their own DNA and ribosomes [1,2]. Among the structurally and functionally divergent plastid family members, chloroplasts contain unique, flattened, sac-like thylakoids that carry out oxygenic photosynthesis and release $\mathrm{O}_{2}$ gas into the atmosphere, while converting atmospheric $\mathrm{CO}_{2}$ into carbohydrates to support plant growth and development [3]. In leaf tissues, chloroplasts are generally distributed in mesophyll, bundle sheath, and epidermal guard cells. Chloroplasts are also present in epidermal pavement cells in many species [2,4,5]. Mesophyll chloroplasts are physiologically important, easily accessible for biochemical and physiological analyses, and therefore have been the primary subject of chloroplast development-related research to date [6-8]. By contrast, non-mesophyll chloroplasts have rarely been the target of chloroplast-focused studies. 
The leaf epidermis is composed of stomatal guard cells, pavement cells, and trichome cells, which may or may not contain chloroplasts depending on the plant species. Basic information on the structure and intracellular morphology of epidermal chloroplasts in the growing leaves of wild-type plants has been collected mainly from two species, tobacco (Nicotiana tabacum) and Arabidopsis thaliana [4,5,9-19], although studies on the control of stomatal opening and closing in several model plants have also generated a vast amount of data on guard cell chloroplasts [3,20-23]. Similarly to mesophyll chloroplasts, pavement and guard cell chloroplasts develop thylakoids (which form stroma lamellae and grana and synthesize chlorophyll pigments), accumulate starch grains in the stroma, and express nuclear- and chloroplast-encoded photosynthetic genes. However, epidermal chloroplasts are smaller, contain fewer thylakoids, and extend more and longer stromules than mesophyll chloroplasts $[5,9,19,24-28]$. Guard cell chloroplasts preferentially accumulate starch grains via a regulatory mechanism that is distinct from that employed by mesophyll cell chloroplasts [10,23]. Furthermore, the chloroplast phenotypes of representative chloroplast division mutants differ significantly between leaf mesophyll cells and pavement or guard cells, indicating tissue- or cell-type-dependent control of chloroplast division in leaves [17,27-33]. These examples raise a fundamental question about the control of chloroplast development in the leaf epidermis, or, more specifically, whether chloroplast biogenesis-related factors in leaf mesophyll cells play an equivalent role in the leaf epidermis [34-36]. Several recent studies have attempted to address this question. For example, Barton et al. [26] performed imaging analyses to detect different sized epidermal leucoplasts and chloroplasts in the white and green leaf sectors of the Arabidopsis variegation mutant, immutans (im) [37,38], respectively. Negi et al. [39] isolated the Arabidopsis green less stomata 1 (gles1) mutant, which contains a defect in the chloroplast envelope-localized TGD5 protein [40] and exhibits impaired chloroplast development and lipid metabolism in leaf guard cells but not in mesophyll cells. More recently, Itoh et al. [41] reported a new mutant, stromule biogenesis altered1 (suba1; allelic to tgd5), which exhibits abnormalities in chloroplast development and autophagic processes in guard cells. These studies suggest a fundamentally conserved, but differentially tuned, regulation of leaf epidermal and mesophyll chloroplasts. However, regulation of epidermal chloroplasts remains largely elusive, and additional efforts are needed to better understand chloroplast development.

Ethylene-dependent Gravitropism-deficient and Yellow-green $\underline{1}$ (EGY1), a member of the SREBP S2P protease gene family, encodes a thylakoid membrane-targeted metalloprotease [42]. Originally, EGY1 was identified in an Arabidopsis mutant that showed defective ethylene-dependent hypocotyl gravitropism and leaf greening phenotypes. The predicted EGY1 protein contains eight transmembrane domains and an N-terminal transit peptide sequence, and it exhibits ATP-independent proteolytic activity in vitro. Under normal growth conditions, the egy1 mutant produces pale leaves, with grana-less mesophyll chloroplasts [42]. Interestingly, the egy1 mutant exhibits hypersensitivity to exogenous application of high ammonium concentrations [43], leaf chlorosis in association with elevated expression of several senescence-associated marker genes (e.g., SAG12 and SEN4) [44], and enhanced leaf variegation phenotype in the var2-5 mutant background [45]. Notably, similar chlorotic phenotypes have been reported in mutants of the orthologous genes from several plant species, including tomato (Solanum lycopersicum) [46], Setaria italica [47], and N. tabacum [48]. This suggests that Arabidopsis EGY1 and its orthologs in other plant species play important roles in leaf chloroplast biogenesis and maintenance, although their contribution to these processes may vary among species.

Recently, we isolated an argon ion $\left({ }^{40} \mathrm{Ar}^{17+}\right)$-irradiated pale green Arabidopsis mutant, Ar50-33-pg1 [49], which carried a single large deletion (940,000 bp) on chromosome 5, encompassing over 40 protein-coding genes, including EGY1. We showed that both Ar50-33-pg1 and another egy1 mutant, egy1-4 [50], exhibited preferential degeneration of mesophyll chloroplast grana, along with progression of leaf chlorosis [49], suggesting that EGY1 is critical for the maintenance of chloroplasts in leaf mesophyll cells. During mutant screening, we noticed chlorophyll deficiency in leaf stomatal guard cells of Ar50-33-pg1, 
which led us to examine the process of chloroplast formation in the leaf epidermis of Ar5033-pg1. Here, we characterize the two loss-of-function mutants of EGY1, and, extending our previous findings [49], reveal the critical involvement of EGY1 in the formation of chloroplasts in guard cells and pavement cells.

\section{Results}

2.1. Chlorophyll Deficiency in the Epidermis of Expanded Leaves of Ar50-33-pg1 and egy1-4 Mutants

During the screening process of Ar50-33-pg1 [49] (Figure 1A), we surveyed defects (other than mesophyll chlorosis) in leaf chloroplast formation. Epifluorescence microscopy analysis of abaxial leaf epidermal peels revealed severe chlorophyll deficiency in the stomatal guard cells of expanded leaves (Figure 1B). Pavement cells also exhibited chlorophyll deficiency (Figure 1C). The severity of chlorophyll deficiency varied moderately among stomata (paired guard cells) and among pavement cells, but guard cells generally exhibited more severe defects than pavement cells. Although rarely, the pavement cells exhibited wild type-like levels of chlorophyll fluorescence. By contrast, none of the guard cells showed a wild type-like phenotype (data not shown).

Generally, the epidermis of expanded wild-type leaves contained spherical to ellipsoidal chloroplasts, with a diameter of 3-4 $\mu \mathrm{m}$ in guard cells and $4-7 \mu \mathrm{m}$ in pavement cells. These results were consistent with the fluorescence and confocal microscopy observations reported previously $[5,15,16,26,30]$. In the leaf epidermis of Ar50-33-pg1, however, little or no chlorophyll fluorescence was detected under normal fluorescence microscopy conditions, and, in most cases, chlorophyll fluorescence signals were barely detected under the maximal strength of excitation and detection conditions (Figure S1). Additionally, it was very difficult to determine the number and size of Ar50-33-pg1 chloroplasts or plastids because of the faint fluorescence signals and heterogeneity within and between cells (data not shown).

A reciprocal backcross between Ar50-33-pg1 and Col confirmed that chlorophyll deficiency in the epidermis of Ar50-33-pg1 was caused by a single recessive mutation, which was attributed to the large $(940 \mathrm{~kb})$ deletion [49]. To determine whether the epidermal chlorophyll defects were caused by the deletion of EGY1 in Ar50-33-pg1, we characterized another egy1 mutant, egy1-4 (Figure 1A), which carries a 5 bp deletion in exon 4 and a 5 bp substitution in the intron 3-exon 4 region of EGY1 [50]. Our segregation analysis (Table S1), rough mapping (by crossing with Ler) [51], and RT-PCR experiments [52] indicated that egy 1-4 is a loss-of-function allele that produces C-terminally truncated but N-terminally intact proteins due to incorrect splicing and frameshift mutation [52]. Microscopic analysis of egy1-4 mutant leaves revealed the presence of achlorophyllous guard cells and pavement cells, similar to those in Ar50-33-pg1 leaves (Figure 1B,C and Figure S1). Moreover, an allelic test between Ar50-33-pg1 and egy1-4 mutants showed that the $\mathrm{F}_{1}$ progeny of both mutants exhibited leaf epidermal chlorophyll deficiency similar to that observed in the parental genotypes (Figure S2), along with the pale phenotype [49]. We further corroborated these results by analyzing the T-DNA insertion (null) mutant, egy1-2 [42]. Both egy1-2 and its $\mathrm{F}_{1}$ progeny (derived from the egy1-2 $\times$ egy1-4 cross) showed phenotypes similar to those of egy1-4 in terms of leaf chlorosis and epidermal chlorophyll deficiency (Figure S3). Therefore, we concluded that the loss-of-function mutation of EGY1 led to chlorophyll deficiency in the leaf epidermis.

To examine whether the epidermal chloroplast defects in egy 1 could be generally applied to other chloroplast biogenesis mutants, we examined the sig2-2 [53,54] and im1 [37] mutants, as references. The sig2-2 mutant exhibits the virescent leaf phenotype, while the im-1 mutant shows the variegation phenotype (Figure 1A). Although young leaves of the sig2-2 mutant were paler than those of Ar50-33-pg1 and egy1-4 mutants, sig2-2 leaves exhibited a relatively modest reduction in chlorophyll fluorescence in both guard cells and pavement cells (Figure 1B,C). In the im-1 mutant, while the green leaf sectors contained both chlorophyll fluorescence signal-positive and -negative pavement and guard cells, the white leaf sectors mostly contained achlorophyllous pavement and guard cells (Figure 1B,C; 
see also [55]). Although in-depth characterizations are required to establish the various phenotypes, these results imply that the epidermal chloroplast phenotype of mesophyll chloroplast biogenesis mutants cannot be deduced easily. The loss-of-function of EGY1 seemed to affect chloroplast formation in the leaf epidermis, with the defect being more severe in guard cells than in pavement cells.
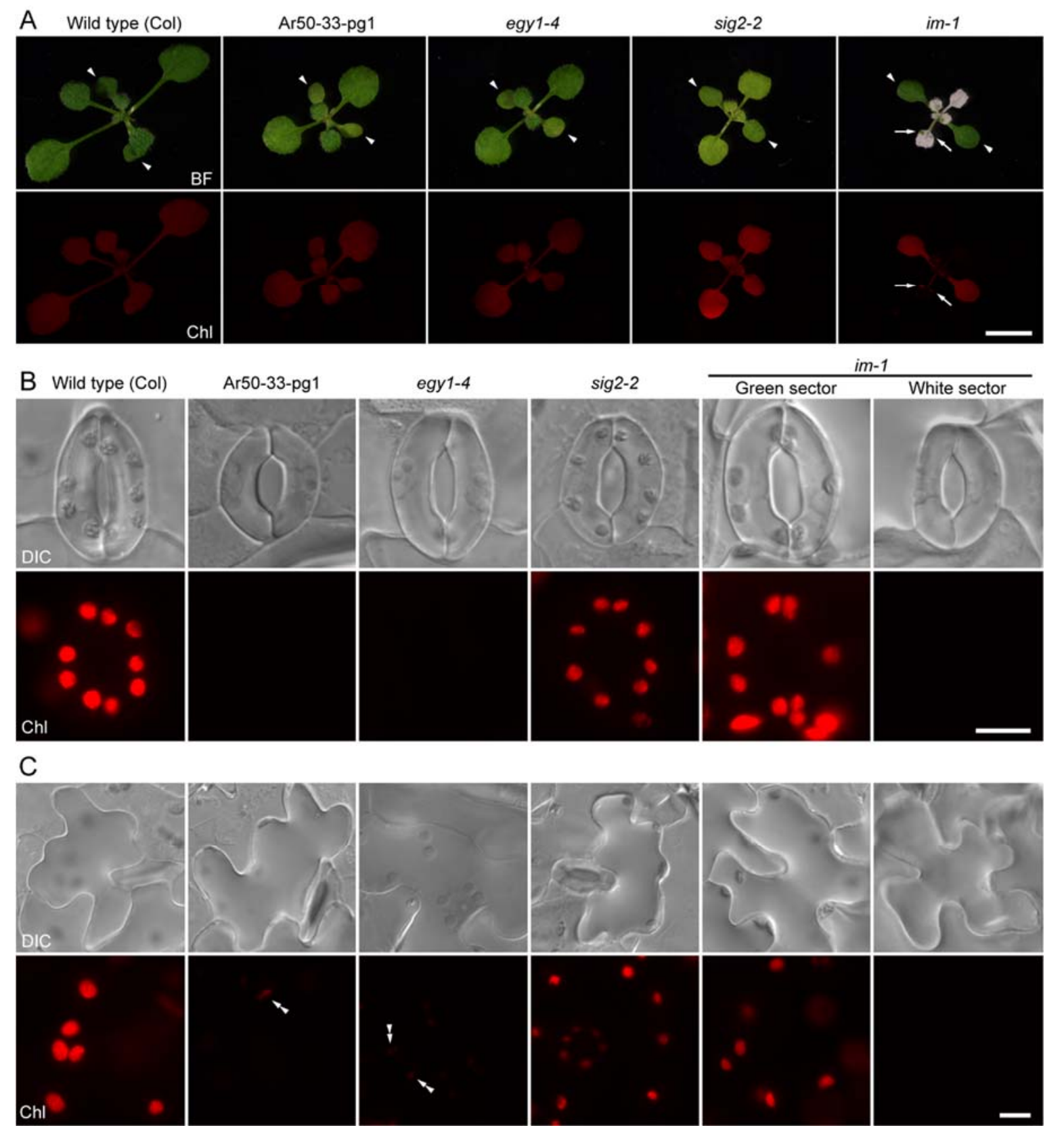

Figure 1. Fluorescence microscopy of the epidermis of fully expanded leaves of wild-type and mutant plants. (A) Photographs of 2-week-old wild-type (Col), Ar50-33-pg1, egy1-4, sig2-2, and im-1 seedlings grown in soil. Arrowheads and arrows indicate cotyledons and green sectors in variegated leaves, respectively. (B,C) Differential interference contrast (DIC) and chlorophyll autofluorescence (Chl) images of guard cells (B) and pavement cells (C) in the abaxial leaf epidermal peels of the primary leaves of 3-week-old seedlings. Double arrowheads in (C) indicate chloroplasts. Chl images in (B,C) were captured under the same microscopic conditions. Bar $=5 \mathrm{~mm}(\mathbf{A})$ and $10 \mu \mathrm{m}(\mathbf{B}, \mathbf{C})$. 


\subsection{Conservation of Epidermal Chlorophyll Deficiency in Expanding Leaves of Ar50-33-pg1 and egy1-4 Mutants}

EGY1 is a positive regulator of chloroplast differentiation in leaf mesophyll cells [42,45], and its loss-of-function induces rapid grana disassembly therein [49]. Epidermal chlorophyll deficiency in expanded egy1 leaves might be accompanied by impaired chloroplast development, chloroplast degeneration after differentiation, or both. We examined this possibility by performing epifluorescence microscopy analysis of the third and fourth leaves (length: 3-5 mm) of 2-week-old wild-type, Ar50-33-pg1, and egy1 seedlings (Figure 1A).

Despite their young developmental stage, the wild-type leaves contained well-developed chloroplasts in mature guard cells. However, no (or barely detectable) chlorophyll fluorescence was observed in Ar50-33-pg1 and egy1-4 guard cells (Figure 2A). The severe attenuation of the chlorophyll fluorescence signal in the guard cells of both mutants was similar to the phenotype of their expanded leaves and was more pronounced than that in phenotype sig2-2, in which guard cells contained developed chloroplasts (Figure 2A).

A
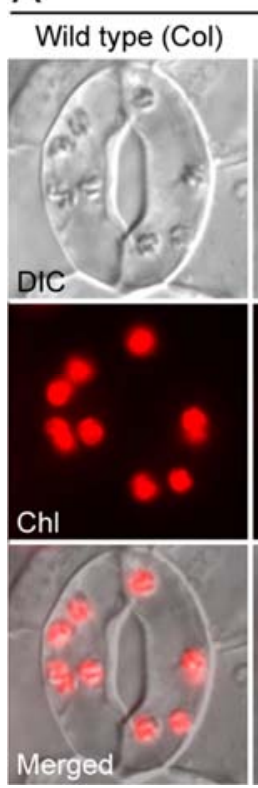

Guard cell
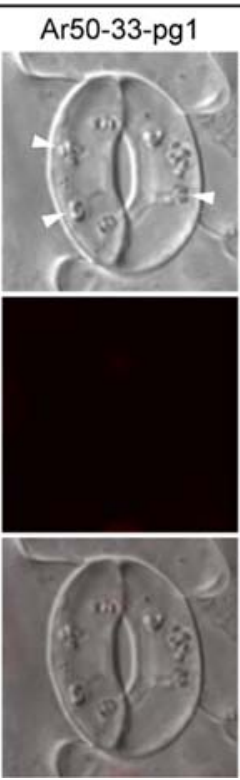

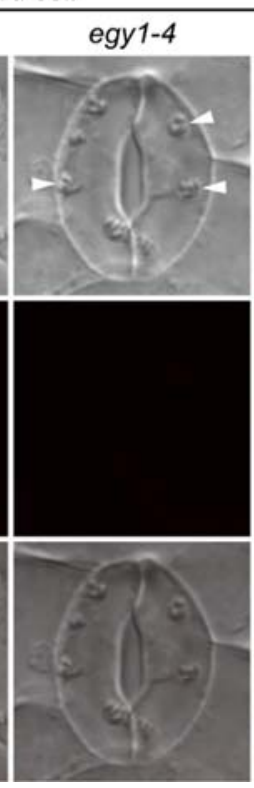

sig2-2

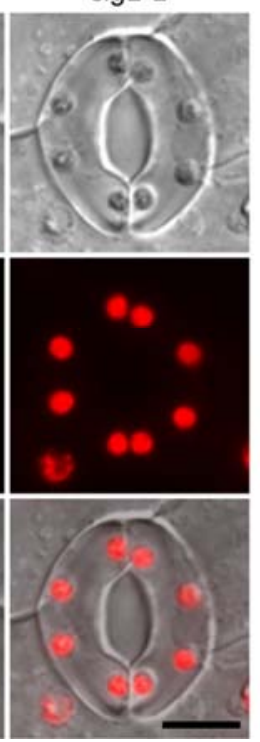

B

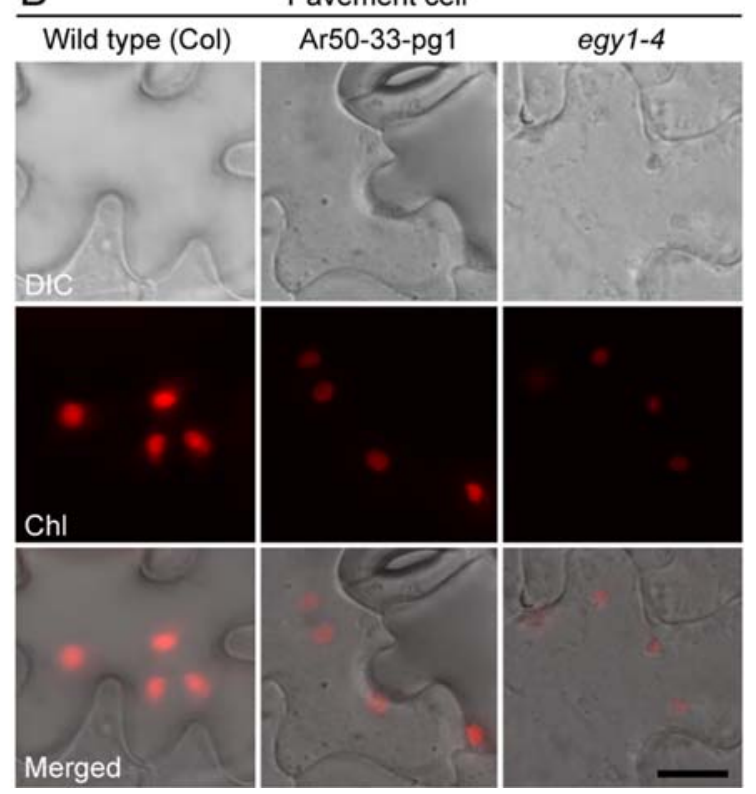

Figure 2. Fluorescence microscopy of the epidermis of expanding wild-type and mutant leaves. (A,B) DIC, chlorophyll autofluorescence $(\mathrm{Chl})$, and merged images of guard cells $(\mathbf{A})$ and pavement cells $(\mathbf{B})$ in the abaxial leaf epidermal peels of the third and fourth leaves of 2-week-old seedlings. Arrowheads indicate putative chloroplasts or plastids. Bar $=10 \mu \mathrm{m}$.

Differentiated chloroplasts, if not fully developed, were observed in the pavement cells of wild-type expanding leaves. The pavement cells showed impaired development of chloroplasts, in terms of both chloroplast size and chlorophyll fluorescence level, in Ar50-33-pg1 and egy1-4 mutants. These chloroplast defects in pavement cells were less severe than those observed in guard cells in both mutants (Figure 2B), and pavement cells showed greater variation in the degree of chloroplast defects than guard cells in both young and mature leaves. However, the nature of chloroplast defects was conserved between expanded (Figure 1C) and expanding (Figure 2B) leaves.

During microscopy analyses, we also noticed the presence of pigment-less spherical substructures in guard cells (Figure 2A, arrowheads). The intracellular localization pattern and size of these structures resembled those of chloroplasts [15] (Figures 1 and 2). Therefore, these structures were considered to represent starch-accumulating chlorophyll-less plastids.

Overall, while mutations in EGY1 permit chloroplast differentiation in leaf mesophyll cells [49], these mutations prevented chloroplast differentiation in guard cells and pavement cells. Additionally, mutations in EGY1 resulted in modest, but distinct, defects in chloroplast development between guard cells and pavement cells. Chloroplast differentia- 
tion was strongly inhibited in guard cells, but weakly or partially inhibited in pavement cells. No particular differences in the epidermal chloroplast phenotypes were detected between Ar50-33-pg1 and egy1-4 mutants.

\subsection{Generation of Transgenic Arabidopsis Lines with Green Fluorescent Protein (GFP)-Labeled Plastids}

Labeling of stroma with fluorescent proteins is a convenient and reliable method for imaging plastids in live plant tissues $[11,18,24,25]$. The strong and constitutive cauliflower mosaic virus $35 S$ promoter (CaMV35S) [56] has been utilized mostly to this end. However, to the best of our knowledge, shoot epidermis-specific promoters $[57,58]$ have never been tested, except for investigating the role of the epidermis in the development of mesophyll chloroplasts [34]. Young epidermal tissues are generally difficult to isolate in an intact and pure form [20].

We generated transgenic Arabidopsis lines expressing the plastid sigma factor 6 (SIG6) transit peptide (TP)-fused synthetic (S65T) GFP (TP SIG6 $_{-}$GFP) gene $[59,60]$ under the shoot epidermis-specific protodermal factor1 (PDF1) promoter [61,62]. The PDF1p::TP SIG6 GFP construct was introduced into wild-type (Col) plants via Agrobacterium-mediated transformation [63]. Several hundred $\mathrm{T}_{1}$ seedlings were obtained by screening for bialaphos resistance conferred by the T-DNA. Among these transformants, relatively strong GFPpositive seedlings were chosen for further screening (Figure S4). The GFP signal intensity, and its localization in tissues, varied moderately among the transgenic lines. However, transgenic lines tended to accumulate GFP at the shoot apex, leaf primordia, and in expanding leaves, forming a fluorescence gradient, which decreased from young to old tissues along the developmental axis (Figure 3A and Figure S4). Finally, the transgenic line FG13-16, which exhibited high and stable GFP fluorescence over three generations, was selected for analysis. GFP localization in the leaf epidermal chloroplasts of FG1316 was confirmed in young leaves and leaf primordia by epifluorescence microscopy (Figure 3B and Figure S5A, and data not shown). These expression patterns of GFP in the leaf epidermis were consistent with the PDF1 promoter activity in shoot protodermal and epidermal tissues reported previously [61,62].
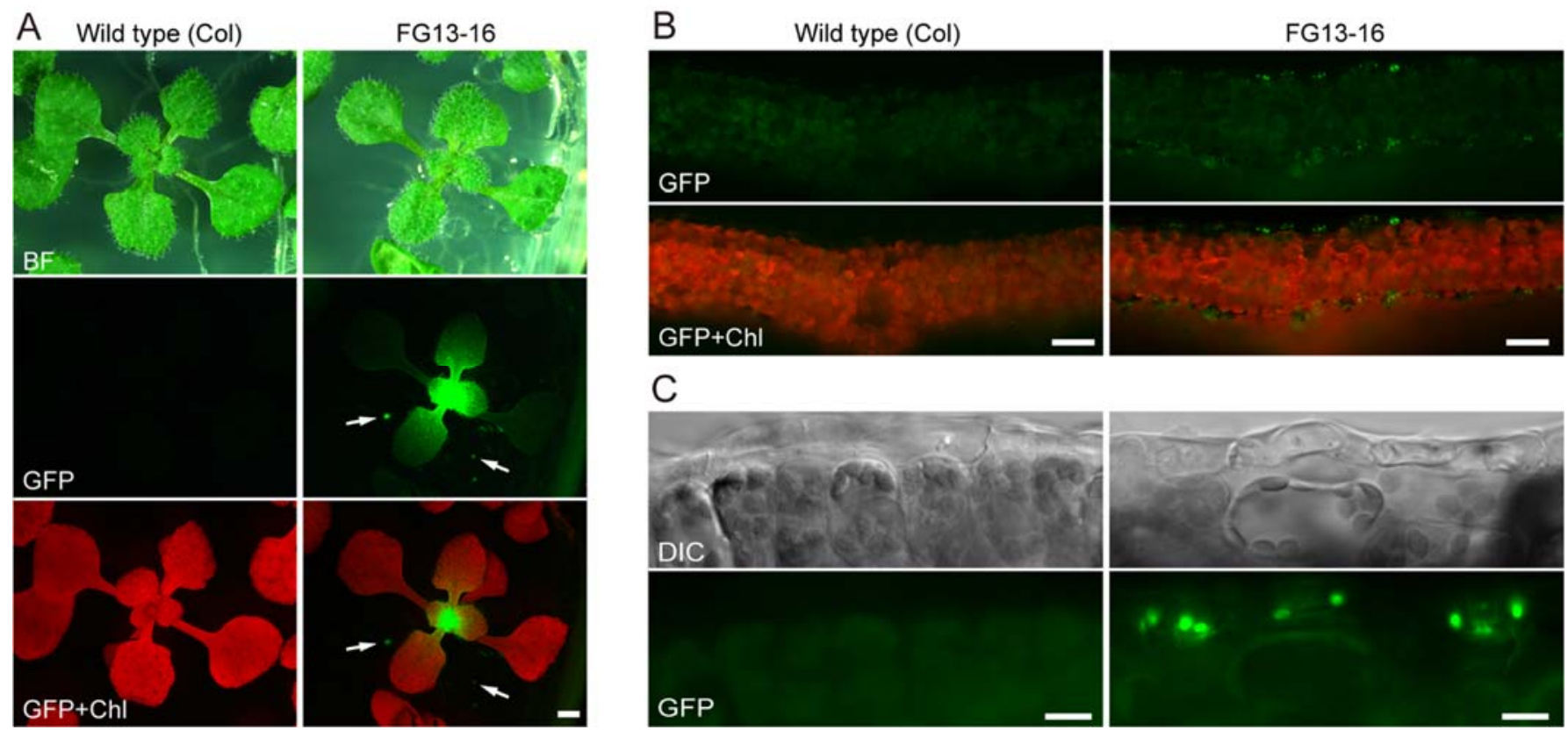

Figure 3. Fluorescence stereomicroscopy and epifluorescence microscopy analyses of 2-week-old wild-type (Col) and

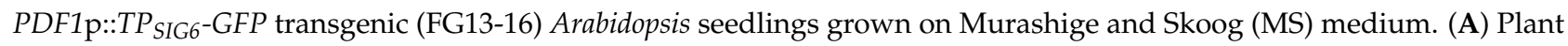
growth. Arrows indicate the local accumulation of GFP in transgenic roots. (B,C) Cross-sections of leaves. DIC, GFP, or chlorophyll autofluorescence (Chl) images or the merged GFP and $\mathrm{Chl}$ images are shown at low (B) and high magnification (C). Bar = $1 \mathrm{~mm}(\mathbf{A}), 50 \mu \mathrm{m}$ (B), and $10 \mu \mathrm{m}(\mathbf{C})$. 
The transgenic plants also showed a GFP signal in roots (Figure 3A, Figures S4 and $\mathrm{S} 5 \mathrm{~B})$, which was localized at the primordia and tip of lateral roots. Under high magnification, GFP-labeled proplastids in primordial cells appeared as discrete intracellular organelles with diverse shapes (globular, amoeboid, and filamentous (Figure S5C)), indicating that these transgenic lines could be used to study plastids during root development. During the reproductive phase, GFP accumulated at the shoot apex (similar to that during the vegetative phase) and the surrounding floral organs (Figure S5D). GFP was also detected in the embryos of siliques (Figure S5E-G). Our preliminary observations, however, indicated that these shoot apex- and embryo-localized GFP signals existed not only in the outermost epidermal tissues but also in internal tissues (data not shown), cautioning that the selection of lines exhibiting strong GFP signals, and therefore efficient chloroplast labeling, did not necessarily reflect the authentic expression of the reference gene (i.e., PDF1) $[61,62,64,65]$ in several tissues. Nevertheless, we concluded, in accordance with the objective of this study, that a plastid-labeled marker line for studying plastids in the epidermis of young shoots was obtained successfully.

\subsection{Visualization of Chlorophyll-Deficient Plastids in the Leaf Epidermis of Ar50-33-pg1 and egy1-4 Mutants}

To generate plastid-labeled lines in the egy1 mutant background, we crossed the FG1316 transgenic line as the male parent with Ar50-33-pg1 or egy1-4 (female parent). In parallel with this experiment, another transgenic line, FL6-5, expressing both AtFtsZ1-1 TP-fused Yellow Fluorescent Protein gene (TP FtsZ1-YFP) and Cryptochrome 2 (Cry2) nuclear localization signal (NLS)-fused Cyan Fluorescent Protein gene (NLS $\left.\mathrm{Cry}_{2}-\mathrm{CFP}\right)$ under the control of the constitutive CaMV35S promoter [32], was crossed with both mutants to obtain another set of fluorescent mutants. The FG13-16-derived lines facilitated the analysis of epidermal chloroplasts in expanding leaves, while the FL6-5-derived lines facilitated the detection of epidermal chloroplasts in expanded leaves with the intense YFP signal.

Guard cells in both expanded and expanding leaves of Ar50-33-pg1 and egy1-4 mutant contained green fluorescent structures, which were spatially merged with the faint chlorophyll fluorescence signals, confirming that these structures were chloroplasts (plastids) (Figure 4A,B, and data not shown). Notably, despite the severe loss of chlorophyll fluorescence, the configuration and intracellular distribution of mutant chloroplasts or plastids in guard cells were largely consistent with those of wild-type chloroplasts. The only difference between wild-type and mutant guard cell plastids, other than the remarkable chlorophyll reduction in mutant plastids, was the modest size reduction in egy1 plastids. Pavement cells in the leaves of both egy 1 mutants also exhibited similar results (Figure 4C,D). Green fluorescent bodies, which merged perfectly with regions emitting chlorophyll fluorescence signals, exhibited a scattered distribution in mutant cells, similar to that observed in wildtype cells (Figure 4C,D, double arrowheads). These pavement cell chloroplasts or plastids in Ar50-33-pg1 and egy1-4 were only moderately reduced in size relative to those in the wild type. 

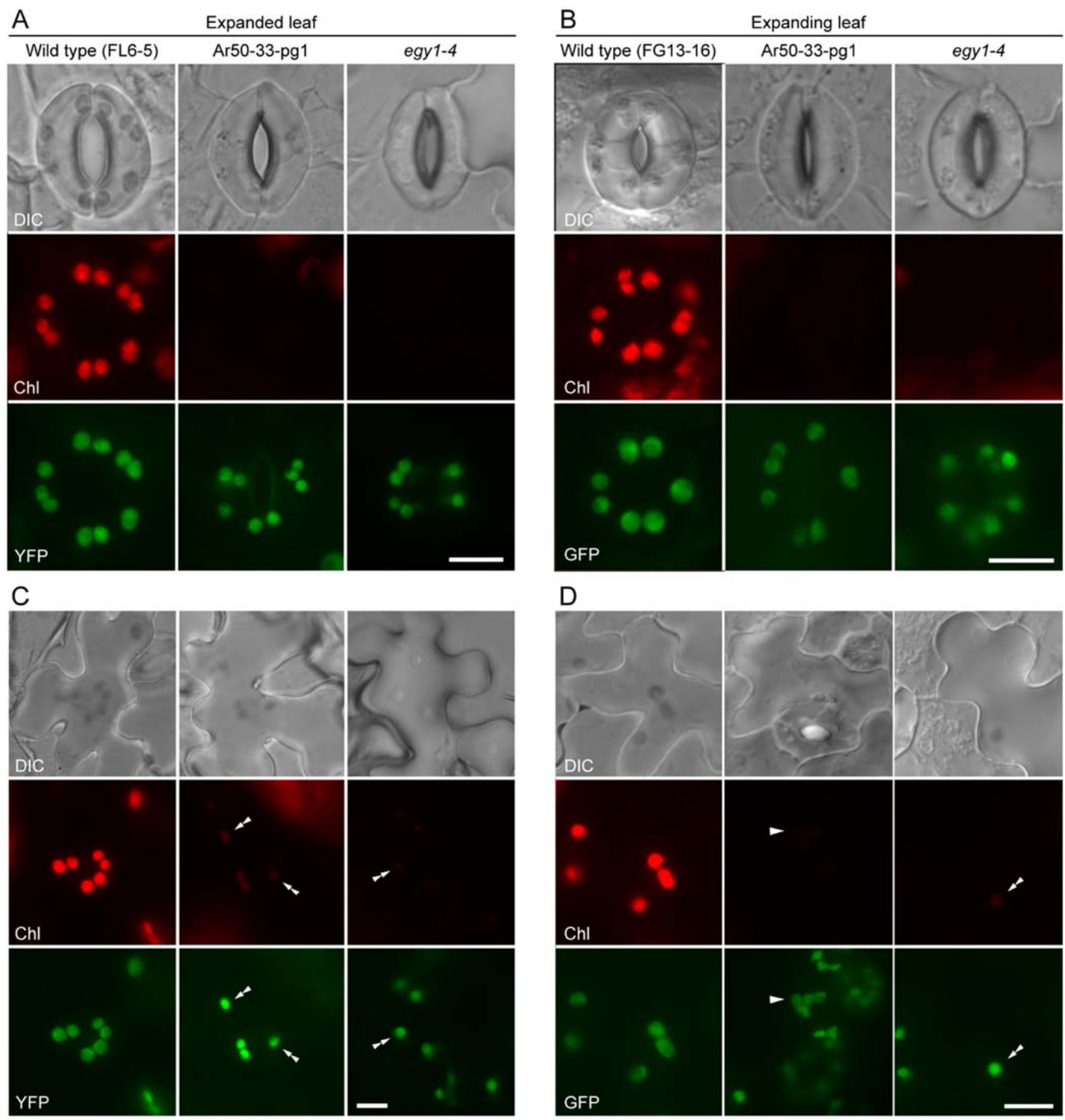

Figure 4. Fluorescence microscopy analysis of leaf epidermis in the wild type and in mutant lines expressing stroma-targeted fluorescent proteins. (A,B) Guard cells in fully expanded (A) and expanding (B) leaves. (C,D) Pavement cells in expanded (C) and expanding (D) leaves. In (A,C), DIC, chlorophyll autofluorescence (Chl) and YFP images of the primary leaves of 3-week-old wild-type (FL6-5), Ar50-33-pg1 (Ar50-33-pg1 × FL6-5), and egy1-4 (egy1-4 × FL6-5) transgenic seedlings are shown, while in (B,D), DIC, Chl, and GFP images of the third and fourth expanding leaves of 18-day-old wild-type (FG13-16), Ar50-33-pg1 (Ar50-33-pg1 × FG13-16), and egy1-4 (egy1-4 × FG13-16) transgenic seedlings are shown. Double arrowheads in (C,D) indicate the presence of chloroplasts. Arrowheads in (D) correspond to those in Figure S6 and indicate pavement cell chloroplasts. Chl images in (A-D) were captured under the same microscopic conditions. Bar $=10 \mu \mathrm{m}$.

To evaluate the effects of mutations in EGY1 on the replication of epidermal cell chloroplasts or plastids, we counted the number of GFP-positive plastids in mature guard

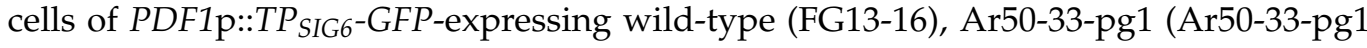


$\times$ FG13-16), and egy1-4 (egy1-4 × FG13-16) seedlings (Table 1). The third and fourth leaves of 18-day-old FG13-16, Ar50-33-pg1 × FG13-16, and egy1-4 × FG13-16 seedlings were examined by epifluorescence microscopy. The results showed that the number of guard cell plastids in Ar50-33-pg1 and egy1-4, both at the single-cell level and stomatal (guard cell pair) level, were similar to that in their wild-type counterparts (data were not significantly different $(p>0.05)$ between samples by the Kruskal-Wallis test). This result was in marked contrast to the previously reported results for arc6 [30,32] and atminE1 [32] mutants, in which non-photosynthetic plastids were capable of massive proliferation in a population of chlorophyll-deficient guard cells, overcoming defects in the chloroplast division machinery, although the underlying mechanism remains unknown. Thus, the shape and number of plastids were unaffected by the absence of chlorophyll in egy1 guard cells, suggesting that the proliferation of chloroplasts does not require a functional EGY1 protein in the leaf epidermis, and the regulatory mechanisms that determine the photosynthetic competence of chloroplasts and the control of chloroplast division can be separated during leaf formation.

Table 1. Plastid number in leaf stomatal guard cells of wild-type plants and mutant lines expressing

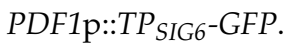

\begin{tabular}{ccccc}
\hline Plant & & $\begin{array}{c}\text { Wild Type } \\
\text { (FG13-16) }\end{array}$ & Ar50-33-pg1 & egy1-4 \\
\hline Chloroplast & Mean \pm SD & $7.3 \pm 1.1$ & $7.6 \pm 1.1$ & $7.8 \pm 1.2$ \\
number & Max & 10 & 10 & 11 \\
per stoma & Min & 5 & 6 & 5 \\
(GC pair) & $\mathrm{n}$ & 50 & 50 & 50 \\
per GC & Mean \pm SD & $3.6 \pm 0.8$ & $3.8 \pm 0.8$ & $3.9 \pm 0.8$ \\
& Max & 6 & 6 & 6 \\
& Min & 2 & 2 & 2 \\
& $\mathrm{n}$ & 100 & 100 & 100 \\
\hline
\end{tabular}

2.5. Conserved Chlorophyll-Deficient Phenotype of Cotyledon Guard Cells of Ar50-33-pg1 and egy1-4 Mutants

We extended our characterization of egy1 mutant guard cells to that of cotyledons. Cotyledons are developed from embryonic cells in seeds, rather than from the shoot apical meristem [3,66], and develop chloroplasts in mesophyll cells, guard cells, and pavement cells (as in leaves). Chloroplast development in cotyledons is believed to be controlled differently from that in leaves, based on the identification of mutants with organ-specific abnormalities in chloroplast biogenesis (e.g., [67-69]). Therefore, the status of cotyledon chloroplasts in egy1 mutants could be of interest.

Guard cells in the mature cotyledons of Ar50-33-pg1 × FG13-16 and egy1-4 × FG13-16 lines exhibited severe chlorophyll deficiency (Figure 5A). The PDF1 promoter in FG13-16 expressed the $T P_{S I G 6}$-GFP fusion specifically in the cotyledon epidermis, which confirmed the preservation of plastids, as in leaf guard cells. No noticeable differences in the size of plastids could be observed between the wild type and egy1 mutants (Figure 5A). On the other hand, mesophyll chloroplasts in cotyledons of the wild-type and mutant lines lacked GFP and seemed to show normal differentiation, based on the chloroplast size and chlorophyll fluorescence (Figure 5B). Although the degeneration phenotype of cotyledon mesophyll chloroplasts was not established and requires substantial inspection in the future, our results indicate that EGY1 is crucial for the formation of guard cell chloroplasts in cotyledons. 


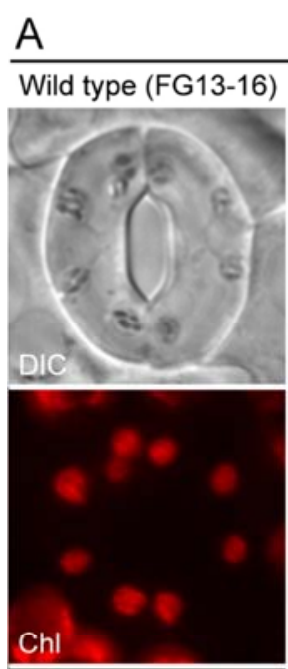

Guard cell
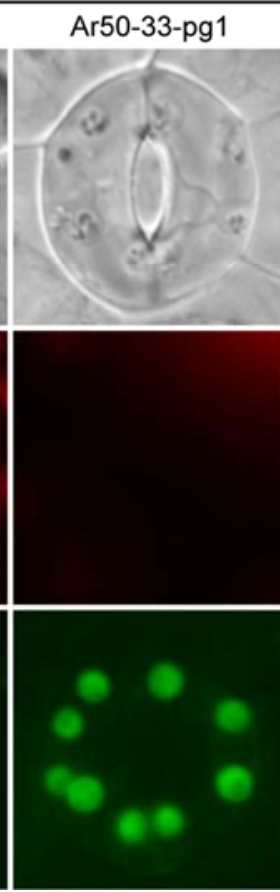

B
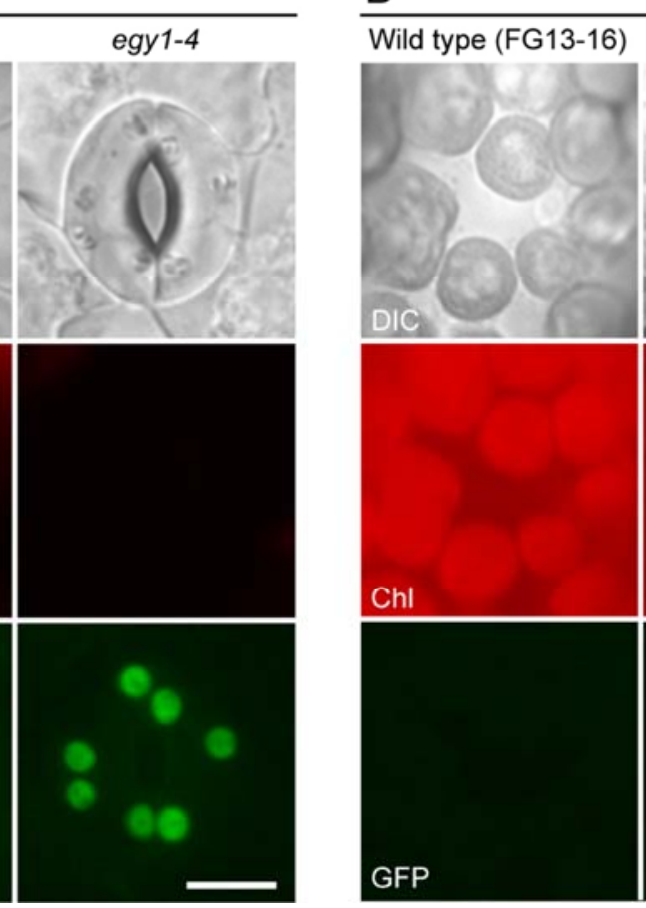

egy 1-4
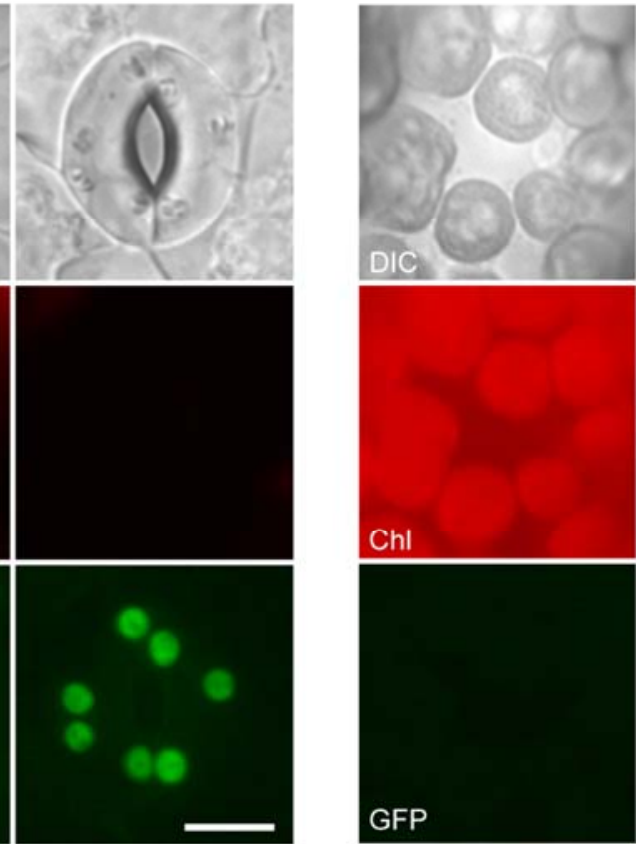

Mesophyll cell

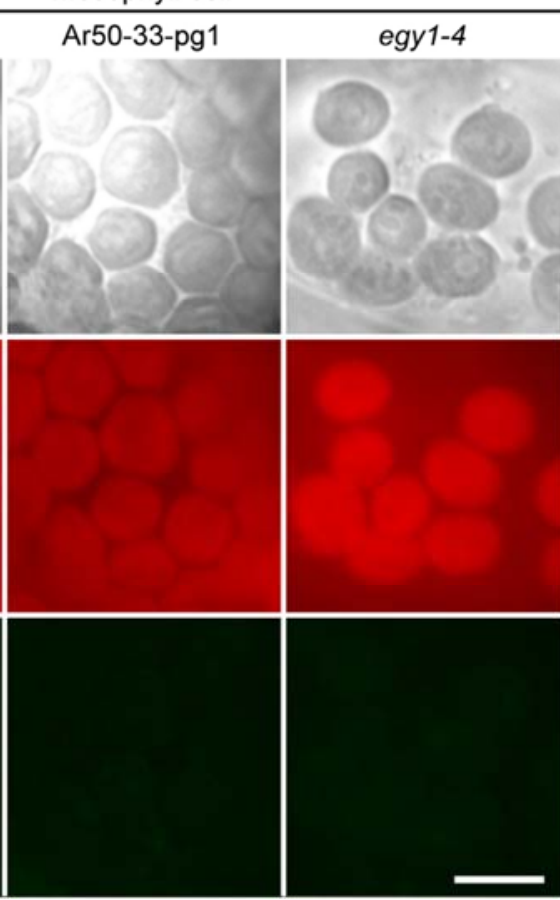

Figure 5. Fluorescence microscopy of cotyledon epidermis in the wild-type and mutant lines expressing stroma-targeted fluorescent proteins. (A,B) DIC, chlorophyll autofluorescence (Chl), and GFP images of guard cells (A) and mesophyll cells

(B) in the abaxial epidermal peels of cotyledons of 1-week-old seedlings. Bar $=10 \mu \mathrm{m}$.

2.6. Chlorophyll Deficiency in Developing Guard Cells in the Leaf Epidermis of Ar50-33-pg1 and egy1-4 Mutants

Stomatal development during leaf expansion involves the unique processes of cell division and expansion through the formation of several progenitor cell types [70]. This program is not strictly limited to the proliferation and differentiation zones of mesophyll cells in the leaf [71,72]. Guard mother cells represent a direct precursor of paired guard cells and contain chloroplasts [10]. While the mesophyll chloroplast development program is generally thought to follow a developmental gradient of leaves along the distal-proximal axis [6,72-74], the development of epidermal chloroplasts, including that of guard cells, remains largely unknown. A significant expansion of chloroplasts (plastids) occurs during the formation of guard cells (length: 3-4 $\mu \mathrm{m}$ ) from guard mother cells (length: 1-2 $\mu \mathrm{m}$ ) [10] (Figures $1 \mathrm{~B}$ and $4 \mathrm{~A}, \mathrm{~B}$ ). We therefore examined the existence and morphology of chloroplasts

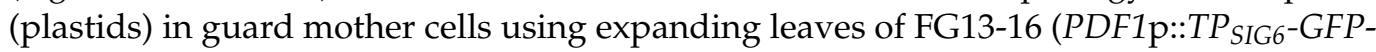
expressing wild type), Ar50-33-pg1 × FG13-16, and egy1-4 × FG13-16 plants.

Guard mother cells in wild-type leaves exhibited chlorophyll autofluorescence in small-sized chloroplasts (Figure 6A). These chloroplasts were frequently highly elongated, with a constriction at the mid-point. Based on our previous observation of FtsZ1 ringmediated chloroplast division in guard cells of expanding leaves [75], these elongated chloroplasts were predicted to be undergoing binary fission [76]. However, guard mother cells in both Ar50-33-pg1 and egy1-4 leaves exhibited no (or barely detectable) chlorophyll autofluorescence. Instead, GFP-labeled plastids, with a normal size and shape, were observed (Figure 6A,B and Figure S6), which coincided with the mature guard cells in expanded and expanding leaves of both Ar50-33-pg1 and egy1-4 mutants. Thus, the lossof-function of EGY1 led to chlorophyll deficiency in leaves during the development of stomatal guard cells (Figure 6B and Figure S6B). 


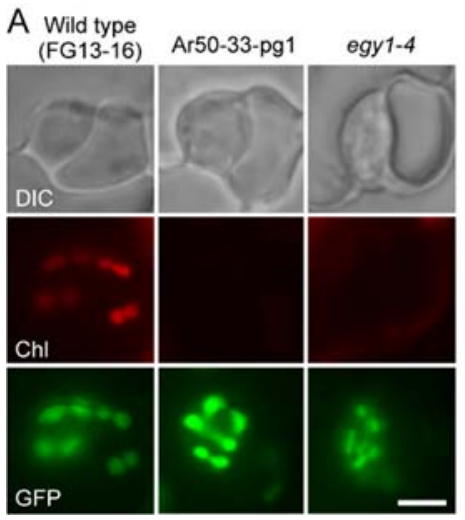

B

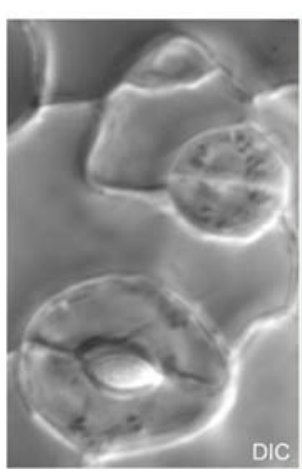

Ar50-33-pg1

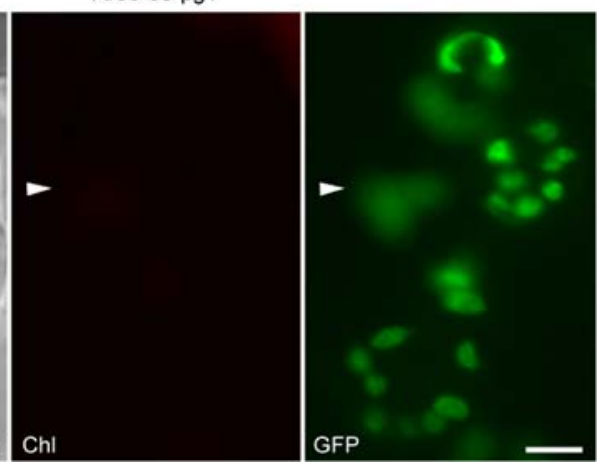

Figure 6. Fluorescence microscopy of leaf guard mother cells in the wild-type and mutant lines expressing PDF1p::TP SIG6 $^{-}$ GFP. (A,B) DIC, chlorophyll autofluorescence (Chl), and GFP images of guard mother cells (A) and late stomatal lineage cells (B) in the abaxial leaf epidermal peels of the third and fourth expanding leaves of 18-day-old seedlings. Arrowheads in (B) correspond to those in Figure 4 and Figure S6 and indicate pavement cell chloroplasts. Chl images in (A,B) were captured under the same microscopic conditions. Bar $=5 \mu \mathrm{m}$.

\subsection{Ultrastructure of Guard Cell Plastids in the Leaf Epidermis of Ar50-33-pg1 and egy1-4}

To investigate the plastid ultrastructure in the chlorophyll-deficient leaf epidermis of Ar50-33-pg1 and egy1-4 mutants, we examined the abaxial epidermis of the primary leaves of 10-day- and 3-week-old wild-type (Col), Ar50-33-pg1, and egy1-4 seedlings by transmission electron microscopy (TEM) (Figures 7-9), as in our recent analyses of mesophyll chloroplasts [49]. Mesophyll cells in 10-day-old plant leaves are expected to occur exclusively at the chloroplast building stage, while those in 3-week-old plants leaves are expected to occur at the stage of chloroplast maintenance to early destruction.

The overall configurations of mature guard cells in both Ar50-33-pg1 and egy1-4 mutants appeared similar to those of the wild type (Figure 7A). The structures of central vacuoles, nuclei, and cell walls in both mutants were also similar to those in the wild type, in accordance with previous observations [10]. At the subcellular level, guard cells in Ar5033-pg1 and egy1-4 leaves contained chloroplasts that produced starch grains similar to the wild-type guard cells; however, the mutant guard cells exhibited defects in the thylakoid structure. Wild-type guard cell chloroplasts contained typical thylakoid systems composed of up to five stacks of granal thylakoids and stromal lamellae running from pole to pole along the longitudinal axis of chloroplasts. By contrast, mutant guard cell chloroplasts contained single-layered thylakoids without grana stacking (Figure 7B). These 'stroma lamellae'-like thylakoids were frequently detected in not only long filamentous forms but also spiral, circular, and short filamentous forms in nearly normal-sized chloroplasts. Moreover, an abnormally large number of electron-dense plastoglobules were detected in mutant chloroplasts. The tubular stroma-containing substructures of plastids, stromules, were occasionally detected in guard cells of both wild-type and egy1 leaves (Figure 7B, and data not shown). 


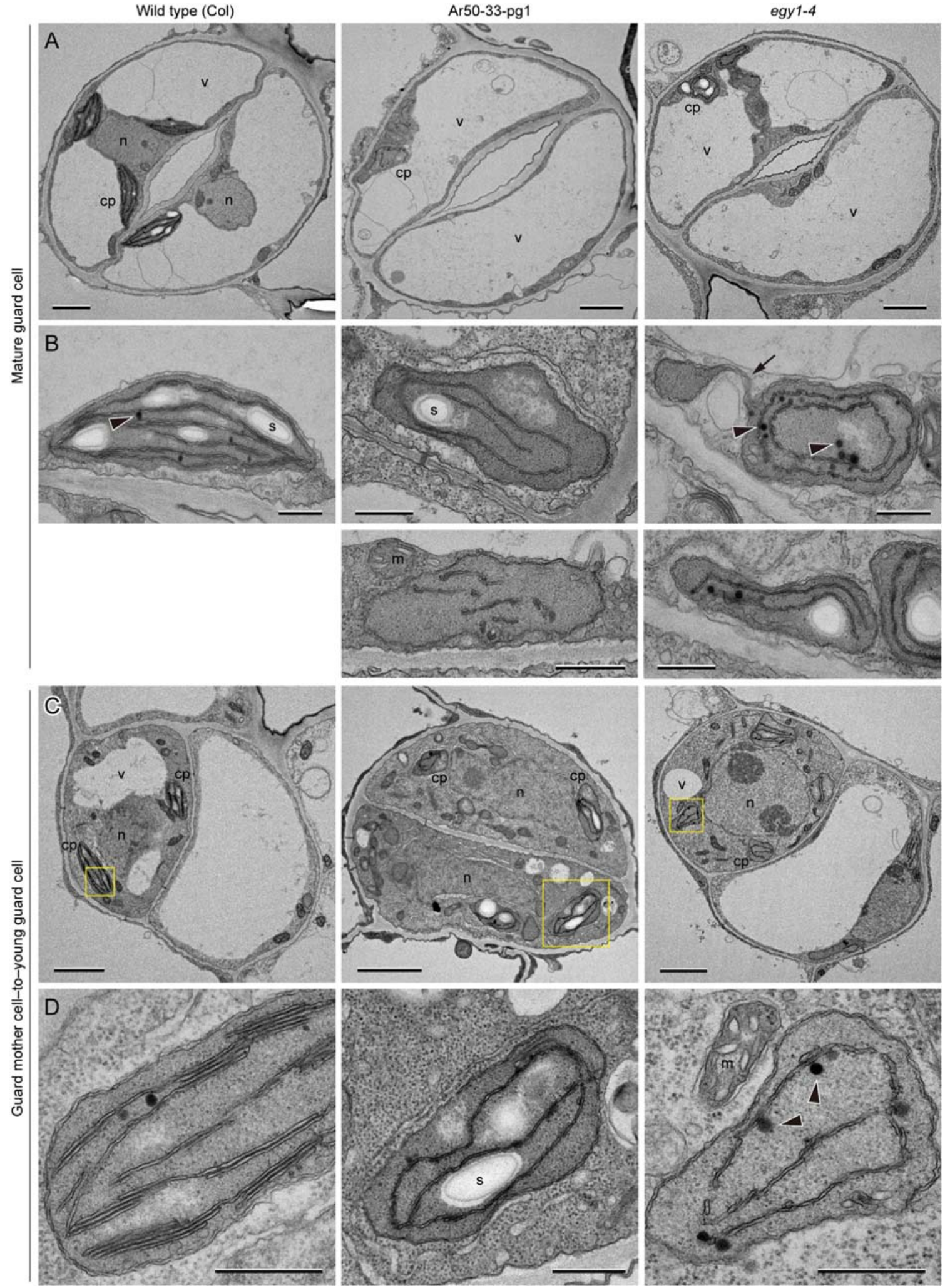

Figure 7. TEM analysis of guard cells and guard mother cells in expanding leaves of wild-type and mutant plants. Primary leaves of 10-day-old wild-type (Col), Ar50-33-pg1, and egy1-4 plants were analyzed. (A,B) Mature guard cells (A) and chloroplasts therein (B). (C,D) Guard mother cells dividing into two guard cells (C), and chloroplasts therein (D). Boxed regions in (C) are magnified in (D) (the image is rotated). Arrows and arrowheads indicate stromules and plastoglobules, respectively. cp, chloroplast; $n$, nucleus; s, starch; v, vacuole. Bar $=2 \mu \mathrm{m}(\mathbf{A}, \mathbf{C})$ and $0.5 \mu \mathrm{m}(\mathbf{B}, \mathbf{D})$. 

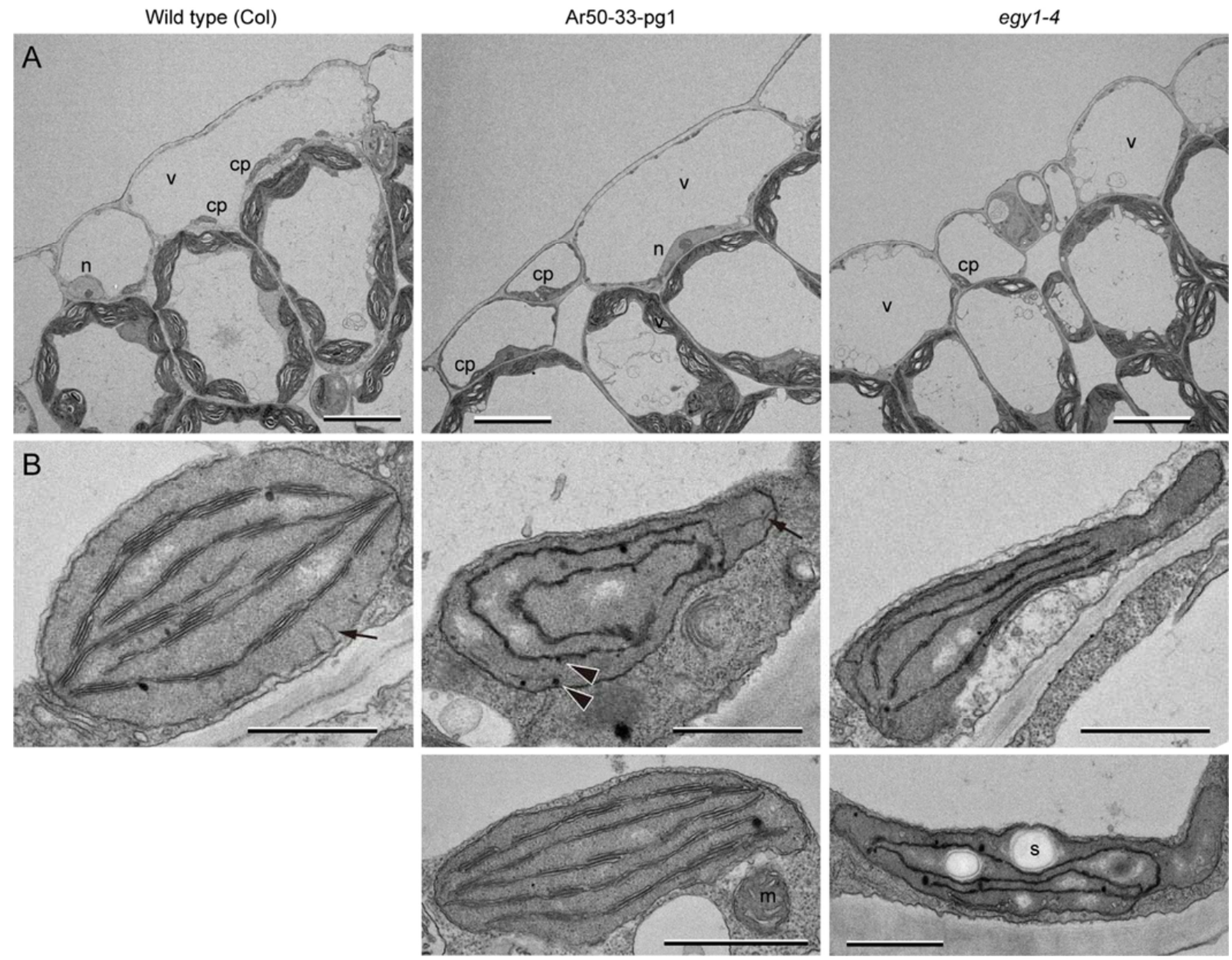

Figure 8. TEM analysis of pavement cells in the expanding wild-type and mutant leaves. Primary leaves of 10-day-old wild-type (Col), Ar50-33-pg1, and egy1-4 plants were analyzed. (A) Pavement cells. (B) Pavement cell chloroplasts. Arrows and arrowheads indicate tubular structures extending from the inner envelope and plastoglobules, respectively. See also Figure S7. Abbreviations: $c p$, chloroplast; n, nucleus; s, starch grain; v, vacuole. Bar $=10 \mu \mathrm{m}(\mathbf{A})$ and $1 \mu \mathrm{m}(\mathbf{B})$.
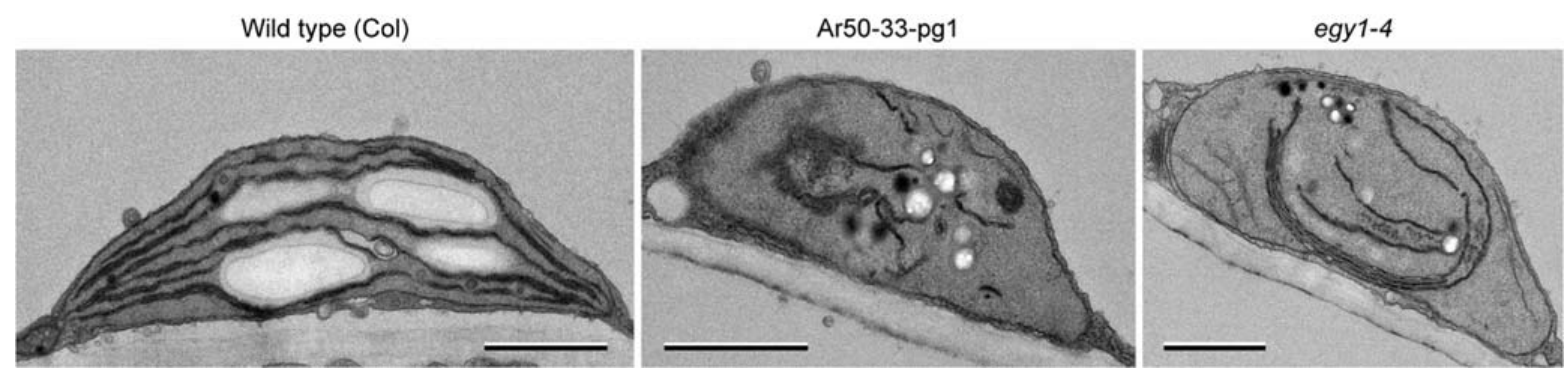

Figure 9. TEM analysis of pavement cells in the fully expanded leaves of wild-type and mutant plants. Primary leaves of 3-week-old wild-type (Col), Ar50-33-pg1, and egy1-4 plants were analyzed. Bar $=1 \mu \mathrm{m}$.

Next, we focused on guard mother cells and young guard cells. The guard mother cells in wild-type leaves developed chloroplasts containing up to five stacks of granal thylakoids (Figure 7C,D). Additionally, the wild-type chloroplasts in guard mother cells accumulated starch grains, consistent with the previous report [10]. Guard mother cells and young guard cells in Ar50-33-pg1 and egy1-4 mutant leaves were indistinguishable from those in wild-type leaves, except for the chloroplast interior structure. Chloroplasts in both Ar50-33-pg1 and egy1-4 mutants contained only single-layered thylakoids in most regions. These thylakoids were occasionally twisted, and two adjacent single-layered thylakoids 
formed a short attachment site or an interconnection. Additionally, although the egy1 mutant chloroplasts could produce starch grains, aberrant thylakoid forms (spirals, circles, or short filaments) were observed, as in the mature guard cell (Figure 7C,D and data not shown).

\subsection{Ultrastructure of Pavement Cell Plastids in the Leaf Epidermis of Ar50-33-pg1 and egy1-4 Mutants}

Next, we examined pavement cells in wild-type and mutant leaves. The overall configurations of pavement cells in Ar50-33-pg1 and egy1-4 mutant leaves were similar to those of pavement cells in wild-type leaves (Figure 8A), which is consistent with the phenotypes of guard cells and mesophyll cells observed in ultrathin leaf sections (Figure 7) [49]. Compared with the guard cell chloroplasts, pavement cell chloroplasts in Ar50-33-pg1 and egy1-4 leaves exhibited greater variations in thylakoid structure. Only single-layered thylakoids to the wild type-like multi-layered (granal) thylakoids were found (Figure 8B and Figure S7, and data not shown). Additionally, the mutant pavement cell chloroplasts contained many plastoglobules and exhibited reduced thickness at the whole organelle level, similar to the phenotype of egy1 mutant guard cell chloroplasts (Figure 7B,D). By contrast, the wild-type pavement cell chloroplasts exhibited a complete lens-like shape, with the basic composition of grana and stromal lamellae. The presence of relatively well-developed chloroplasts in the pavement cells of Ar50-33-pg1 and egy1-4 leaves (Figure 8B) supported the data obtained by epifluorescence microscopy in this study.

Finally, we examined the epidermal chloroplasts in the leaves of 3-week-old wild-type, Ar50-33-pg1, and egy1-4 seedlings (Figure 9 and Figure S8). Guard cells and pavement cells in wild-type leaves contained chloroplasts with well-developed thylakoids. The accumulation of starch grains, a characteristic feature of guard cell chloroplasts [10,22,23], was also confirmed (Figure S8). By contrast, the egy1 mutant guard cell and pavement cell chloroplasts contained heavily damaged or disorganized thylakoids (Figures 7 and 8 and Figure S7). Typically, egy1 thylakoids lacked grana and did not orient to the chloroplast poles, but instead assumed the extended single-layered, spiral, circular, or short filamentous forms. Multi-layered thylakoids with certain intervals were also occasionally formed. Chloroplasts in egy1 mutant leaves showed some structural differences, depending on plant age; chloroplasts in the leaves of 3-week-old mutant plants contained more plastoglobules and damaged thylakoids compared with chloroplasts in those of 10-day-old mutant plants.

Taken together, the results of ultrastructure analysis (Figures 7-9) supported our fluorescence microscopy observations of chloroplasts in guard cells and pavement cells (Figures 1, 2, 4 and 6, Figures S1 and S6). The remarkable reduction in chlorophyll fluorescence in Ar50-33-pg1 and egy1-4 mutants was associated with defects in thylakoid structure. Moreover, the relatively broad chlorophyll deficiency phenotypes of egy1 mutant pavement cells may correspond to the degree of structural anomalies in their thylakoids. Throughout the fluorescence and electron microscopy analyses, the epidermal chloroplast phenotypes of Ar50-33-pg1 and egy1-4 mutants were indistinguishable. In conclusion, the results of our current mutant analyses indicate that EGY1 is involved in the proper organization of thylakoids in epidermal cell chloroplasts, and that this involvement is critical for the formation of guard cell chloroplasts during stomata development.

\section{Discussion}

In this study, following the initial characterization of a heavy-ion-induced pale green mutant, Ar50-33-pg1 [49], we investigated the role of a chloroplast protein-coding gene, EGY1 [42], in leaf epidermal chloroplasts by epifluorescence and electron microscopy, and consequently revealed a novel role for EGY1 function in the control of epidermal chloroplast development. Chloroplast distribution in the leaf epidermis has been documented in the previous literature, and this fact has been described and argued by several landmark studies $[2,4,5,26,34,77]$. To date, however, systematic analyses of the phenotypes of mesophyll, pavement, and guard cell chloroplasts in the mesophyll chloroplast biogenesis mutants, have not been performed, with a few exceptions. Here, we report that EGY1 
encodes a critical factor involved in the biogenesis of epidermal chloroplasts-in particular the differentiation of guard cell chloroplasts-although mutations in EGY1 permitted the development of mesophyll chloroplasts in mutant leaves [49]. The previous finding that egy1 mutants possess chlorophyll-less amyloplasts in the hypocotyl endodermis [78], together with our current comparative analysis of epidermal chloroplast formation in egy1 and sig2-2 mutants, suggests that EGY1 has a greater impact on the formation of nonmesophyll chloroplasts than mesophyll chloroplasts in green tissues of Arabidopsis plants. While a vast number of studies have identified many organ- or tissue-specific chloroplast biogenesis mutants or cultivars based on leaf coloration phenotypes [55,79-81], these leaf phenotypes were visually dissected on a two-dimensional scale in most cases. Nevertheless, tissue-specific defects in chloroplast formation due to a particular gene mutation can occur along the z-axis of leaf blades involving the leaf epidermis.

The results of the current study raise many questions: (i) How is the development of epidermal chloroplasts in guard cells and pavement cells spatially controlled during leaf formation? (ii) How and why do EGY1 mutations affect the differentiation of leaf epidermal chloroplasts, especially guard cell chloroplasts, more severely than that of mesophyll chloroplasts? (iii) What is the most crucial factor controlling chloroplast development in non-mesophyll tissues? (iv) What is the physiological significance of epidermal chloroplasts, besides their involvement in leaf coloration (e.g., [77]), cuticle development (e.g., [82]), stomatal opening and closing (e.g., [23,39,83,84]), abiotic stress signaling (e.g., [85]), and plant defense (e.g., [86-88])? (v) To what extent are mechanisms underlying the development of mesophyll and non-mesophyll chloroplasts conserved or divergent among plant species? These questions should be addressed in future studies using various experimental approaches.

The current knowledge of leaf development may provide clues for tackling these questions. To answer question (i), approximately $50 \%$ of the pavement cells in mature leaves are predicted to be derived from the stomatal lineage [72]. For instance, during the proliferation of meristemoids, asymmetric division supplies both meristemoids and pavement cells as daughter cells, and such stomatal lineage-derived pavement cells might differ from the other pavement cells in terms of the control of epidermal chloroplast development. Various phenotypic characteristics of egy1 pavement cell chloroplasts could thus be attributed to the developmental heterogeneity of pavement cells. We are currently investigating this possibility using the leaves of egy1 mutants. Additionally, regarding question (ii), data publicly available in the eFP browser [89] show that EGY1 mRNAs accumulate to higher levels in leaf guard cells than in mesophyll cells, indicating that the higher concentration of the EGY1 protein in guard cell chloroplasts might reflect its greater physiological significance compared with that of mesophyll cell chloroplasts. Nevertheless, the substrate of the EGY1 protease remains unknown, and substantial experimental evidence would be required to support the above notion.

From a morphological point of view, unusual thylakoid structures found in Ar5033-pg1 and egy1-4 mutants deserve extensive arguments based on comparisons with previously reported mutant or wild-type chloroplast research. For example, the structural features of thylakoids in egy 1 mutant epidermal chloroplasts, i.e., single-layered, spiral, and circular, were similar to those of cotyledon mesophyll chloroplasts, which differentiated from etioplasts immediately after light irradiation [90]. Furthermore, thylakoids in the leaf mesophyll chloroplasts of the constitutively photomorphogenic 1-6 (cop1-6) Arabidopsis mutant bear a significant resemblance to those in the mesophyll chloroplasts of egy1 mutants [91]. These data suggest that thylakoids in cop1-6, Ar50-33-pg1, and egy1-4 mutants exhibit a common growth arrest phenotype during chloroplast differentiation. According to this assumption, EGY1 might be critical for the biogenesis of thylakoid membranes in the early to middle stages of chloroplast differentiation, although the mechanisms underlying the formation of spiral, circular, and interconnected thylakoids remain unknown. Additionally, it is possible that grana degeneration, as found in the mesophyll chloroplasts of egy1 mutants [49], contributes to the thylakoid architecture of guard cell and 
pavement cell chloroplasts in the leaf epidermis. Given the increased accumulation of plastoglobules in both epidermal cell types in the leaves of 10-day- and 3-week-old plants (Figure 7B,D, Figures 8B and 9), it is possible that the balance between thylakoid biogenesis and degeneration processes determines the terminal phenotype of leaf epidermal chloroplasts in egy1 mutants.

\section{Materials and Methods}

\subsection{Plant Materials and Growth Condition}

Arabidopsis thaliana accession Columbia ( $\mathrm{Col})$ was used as the wild type in this study. All mutants used in this study were also generated in the Col genetic background. Two ${ }^{40} \mathrm{Ar}^{17+}$-irradiated mutants, Ar50-33-pg1 [49] and egy1-4 (originally Ar-28-pg1) [50], were generated previously. Two chloroplast biogenesis mutants, sig2-2 [53,54] and im-1 [37], were provided by RIKEN BRC (originally SALK_006646C [92]; psy01036; Tsukuba, Japan) and Nottingham Arabidopsis Stock Centre (CS3639; Leicestershire, UK), respectively. A fluorescent transgenic line, FL6-5, expressing a plastid stroma-targeted YFP and nucleustargeted CFP under the control of the CaMV35S promoter, was previously described [32]. Seeds of all genotypes were surface-sterilized and sown on Jiffy-7 (AS Jiffy Products, Stange, Norway) or on MS agar media [93] (Wako, Osaka, Japan) supplemented with Gamborg's B5 vitamins and $3 \%(w / v)$ sucrose. All plants were grown under a long-day photoperiod, as described previously [32].

\subsection{Microscopy}

To observe the live tissues of Arabidopsis plants, epifluorescence microscopy and fluorescence stereomicroscopy were performed as described previously $[31,33]$. To perform epifluorescence microscopy, either excised organs or epidermal peels obtained from the abaxial surface of leaves or cotyledons were mounted on glass slides and observed under an Olympus IX71 microscope (Tokyo, Japan). Optical filters and objective lenses used for the detection of chlorophyll autofluorescence, and GFP and YFP signals, have been described previously [33]. To perform fluorescence stereomicroscopy, whole seedlings or excised organs were observed under a Leica MZ10 F microscope (Heidelberg, Germany). Standard band-path and long-path filters and objective lenses $(0.63 \times$ and $1.60 \times$; Leica Microsystems, Wetzlar, Germany) were used to detect chlorophyll autofluorescence and GFP and YFP signals.

The ultrastructure of leaf epidermal plastids was analyzed by TEM. Briefly, leaf samples were collected and subjected to primary chemical fixation, as described previously [49]. Subsequent processes of secondary fixation, dehydration, and preparation of ultrathin sections were performed by Tokai Electron Microscopy Inc. (Nagoya, Japan), as described previously [27].

The obtained digital gray-scale images were processed using Photoshop (Adobe Systems, San Jose, CA, USA) and ImageJ (v1.48, National Institute of Health, Bethesda, MD, USA) to obtain pseudo-colored and merged images. In each panel of Figures 1-6 and Supplementary Figures S1-S5, GFP and chlorophyll fluorescence images were taken under the same excitation and detection conditions, respectively.

\subsection{Generation of Transgenic Arabidopsis Lines with GFP-Labeled Plastids in the Leaf Epidermis}

To specifically label epidermal plastids in the shoot tissues of $A$. thaliana, the stromatargeted synthetic (S65T) GFP [59] was used as a reporter. The N-terminal fusion of GFP with the SIG6 (formerly known as SigF [60]) TP was expressed in Arabidopsis plants under the control of the PDF1 promoter [61,62]. To construct the PDF1p::TP SIG6 $^{-G F P}$ plasmid, a $1.5 \mathrm{~kb}$ sequence upstream of the PDF1 gene was amplified from the genomic DNA of Col plants by PCR using two gene-specific primers, PDF1-4 (TCCTGAAGCTTTGAATTTAAAA CATTTTTTTTTATATATATAG) and PDF1-5 (ATACCCTCGAGTTTATGAGAATTCA CTGAGATTCAGAGAG) (italicized nucleotides represent restriction sites), and PrimeStar DNA polymerase (Takara, Osaka, Japan). PCR was conducted on a thermal cycler (model 
T100; Bio-Rad, Hercules, CA, USA) under the following conditions: 45 cycles of denaturation at $95{ }^{\circ} \mathrm{C}$ for $25 \mathrm{~s}$, annealing at $60^{\circ} \mathrm{C}$ for $30 \mathrm{~s}$, and extension at $72{ }^{\circ} \mathrm{C}$ for $1 \mathrm{~min}$ $50 \mathrm{~s}$. The PCR product was digested with HindIII and XhoI restriction endonucleases and then ligated into the pF-TP-GFP vector (provided by Drs. K. Tanaka and Y. Niwa) [60], which were predigested with HindIII and SalI to delete the CaMV35S promoter from

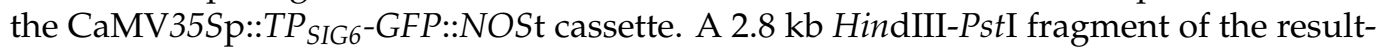
ing plasmid, corresponding to the PDF1p::TP SIG -GFP cassette, was introduced into the pSMAB-Z1TP-sC vector [17] (the original binary vector was provided by Dr. H. Ichikawa) by simultaneously deleting the $35 \mathrm{Sp}:: T P_{F t s Z 1}-C F P$ cassette. The resulting binary vector, pSMAB-PDF1p2-FTP-GFP (13.0 kb), was transformed into Agrobacterium tumefaciens strain C58 by the freeze-thaw method. Agrobacterium-mediated transformation of wild-type (Col) plants was performed using the floral dip method [63]. Over 800 transformed $\left(\mathrm{T}_{1}\right)$ seedlings were selected on MS media containing $10 \mu \mathrm{g} / \mathrm{mL}$ bialaphos, and $15 \mathrm{~T}_{1}$ seedlings were selected to examine the strength, localization, and stability of the GFP signal by fluorescence stereomicroscopy. Finally, one stable transgenic line, designated as FG13-16, was chosen for the microscopic analysis of epidermal chloroplasts.

Supplementary Materials: The following are available online at https://www.mdpi.com/article/ 10.3390/plants10061254/s1. Figure S1: Fluorescence microscopy analysis of the epidermis of fully expanded leaves of wild-type and mutant plants; Figure S2: Phenotypic characterization of the $\mathrm{F}_{1}$ progeny of Ar50-33-pg1 and egy1-4 by fluorescence microscopy; Figure S3: Phenotypic characterization of the T-DNA insertion mutant egy1-2 and the $\mathrm{F}_{1}$ progeny of egy1-2 and egy1-4. Figure S4: Generation of transgenic Arabidopsis lines expressing PDF1p::TP SIG6 $^{-G F P}$; Figure S5: Characterization of the PDF1p::TP $P_{S I G 6}-G F P$ transgenic line FG13-16; Figure S6: Fluorescence microscopy of leaf guard mother cells in mutant plants expressing PDF1p::TP $P_{\text {SIG }}-G F P$; Figure S7: TEM analysis of mesophyll and pavement cells in an expanding leaf of Ar50-33-pg1 mutant plants; Figure S8: TEM analysis of guard cells in fully expanded leaves of wild-type (Col) and Ar50-33-pg1 mutant plants. Table S1: Segregation analysis and allelism test of egy1-4.

Author Contributions: Conceptualization, T.A., Y.K. and M.T.F.; resources, R.D.I., K.K. and T.A.; investigation, A.S., R.M., S.S. (Shiho Sato), M.S., S.S. (Shun Sasaki), H.I., Y.F., M.A., S.O., Y.K. and M.T.F.; writing—original draft, A.S. and M.T.F.; writing—review and editing, R.D.I., Y.K. and M.T.F. All authors have read and agreed to the published version of the manuscript.

Funding: This research was supported by Grants-in-Aid for Scientific Research (KAKENHI No. 20H03297, 20K21449 to Y.K. and 19K05831 to M.T.F.) from the Ministry of Education, Culture, Sports, Science and Technology (MEXT), Japan.

Institutional Review Board Statement: Not applicable.

Informed Consent Statement: Not applicable.

Data Availability Statement: Data is contained within the article or supplementary material.

Acknowledgments: We thank Tokai Electron Microscopy Inc. for supporting the electron microscopy analyses. We also thank RIKEN BRC and NASC for providing seeds of various Arabidopsis mutants. We also thank Kan Tanaka, Yasuo Niwa, and Hiroaki Ichikawa for providing plasmids, and Nobuhiro Suzuki, Tsuyoshi Araki, Nobuyuki Kanzawa, Kensuke Hayashi, Tamao Saito, and Hiroyasu Motose for providing advice. A.S. was supported by a Japanese Government (MEXT) Scholarship (SGU research student category) and the Research Associate Program of Sophia University from 2018-2021.

Conflicts of Interest: The authors declare no conflict of interest. The funders had no role in the design of the study; in the collection, analyses, or interpretation of data; in the writing of the manuscript, or in the decision to publish the results.

\section{References}

1. Wise, R.R. The diversity of plastid form and function. In The Structure and Function of Plastids; Wise, R.R., Hoober, J.K., Eds.; Springer: Dordrecht, The Netherlands, 2007; Volume 23, pp. 3-26. [CrossRef]

2. Pyke, K. Plastid Biology, 1st ed.; Cambridge University Press: Cambridge, UK, 2009; ISBN 978-0521-71197-5. 
3. Taiz, L.; Zeiger, E.; Møller, I.M.; Murphy, A. Plant Physiology and Development, 6th ed.; Sinauer Associates Inc.: Sunderland, MA, USA, 2015.

4. Dupree, P.; Pwee, K.-H.; Gray, J.C. Expression of photosynthesis gene-promoter fusions in leaf epidermal cells of transgenic tobacco plants. Plant J. 1991, 1, 115-120. [CrossRef]

5. Barton, K.A.; Schattat, M.H.; Jakob, T.; Hause, G.; Wilhelm, C.; Mckenna, J.F.; Máthé, C.; Runions, J.; Van Damme, D.; Mathur, J. Epidermal pavement cells of Arabidopsis have chloroplasts. Plant Physiol. 2016, 171, 723-726. [CrossRef] [PubMed]

6. Mullet, J.E. Chloroplast development and gene expression. Annu. Rev. Plant Physiol. Plant Mol. Biol. 1988, 39, 475-502. [CrossRef]

7. Pyke, K.A. Plastid division and development. Plant Cell 1999, 11, 549-556. [CrossRef]

8. Pyke, K. Plastid biogenesis and differentiation. In Cell and Molecular Biology of Plastids, Topics in Current Genetics; Bock, R., Ed.; Springer: Berlin/Heidelberg, Germany, 2007; Volume 19, pp. 1-28. [CrossRef]

9. Robertson, E.J.; Pyke, K.A.; Leech, R.M. arc6, an extreme chloroplast division mutant of Arabidopsis also alters proplastid proliferation and morphology in shoot and root apices. J. Cell Sci. 1995, 108, 2937-2944. [CrossRef] [PubMed]

10. Zhao, L.; Sack, F.D. Ultrastructure of stomatal development in Arabidopsis (Brassicaceae) leaves. Am. J. Bot. 1999, 86, 929-939. [CrossRef] [PubMed]

11. Natesan, S.K.A.; Sullivan, J.A.; Gray, J.C. Stromules: A characteristic cell-specific feature of plastid morphology. J. Exp. Bot. 2005, 56, 787-797. [CrossRef]

12. Streb, S.; Delatte, T.; Umhang, M.; Eicke, S.; Schorderet, M.; Reinhardt, D.; Zeeman, S.C. Starch granule biosynthesis in Arabidopsis is abolished by removal of all debranching enzymes but restored by the subsequent removal of an endoamylase. Plant Cell 2008, 20, 3448-3466. [CrossRef] [PubMed]

13. Schattat, M.; Barton, K.; Baudisch, B.; Klösgen, R.B.; Mathur, J. Plastid stromule branching coincides with contiguous endoplasmic reticulum dynamics. Plant Physiol. 2011, 155, 1667-1677. [CrossRef]

14. Schattat, M.H.; Griffiths, S.; Mathur, N.; Barton, K.; Wozny, M.R.; Dunn, N.; Greenwood, J.S.; Mathur, J. Differential coloring reveals that plastids do not form networks for exchanging macromolecules. Plant Cell 2012, 24, 1465-1477. [CrossRef]

15. Higaki, T.; Kutsuna, N.; Hosokawa, Y.; Akita, K.; Ebine, K.; Ueda, T.; Kondo, N.; Hasezawa, S. Statistical organelle dissection of Arabidopsis guard cells using image database LIPS. Sci. Rep. 2012, 2, 405. [CrossRef]

16. Higa, T.; Suetsugu, N.; Kong, S.-G.; Wada, M. Actin-dependent plastid movement is required for motive force generation in directional nuclear movement in plants. Proc. Natl. Acad. Sci. USA 2014, 111, 4327-4331. [CrossRef]

17. Fujiwara, M.T.; Kojo, K.H.; Kazama, Y.; Sasaki, S.; Abe, T.; Itoh, R.D. The Arabidopsis minE mutation causes new plastid and FtsZ1 localization phenotypes in the leaf epidermis. Front. Plant Sci. 2015, 6, 823. [CrossRef] [PubMed]

18. Delfosse, K.; Wozny, M.R.; Jaipargas, E.A.; Barton, K.A.; Anderson, C.; Mathur, J. Fluorescent protein aided insights on plastids and their extensions: A critical appraisal. Front. Plant Sci. 2016, 6, 1253. [CrossRef]

19. Erickson, J.L.; Kantek, M.; Schattat, M.H. Plastid-nucleus distance alters the behavior of stromules. Front. Plant Sci. 2017, 8, 1135. [CrossRef]

20. Zeiger, E.; Talbott, L.D.; Frechilla, S.; Srivastava, A.; Zhu, J. The guard cell chloroplast: A perspective for the twenty-first century. New Phytol. 2002, 153, 415-424. [CrossRef]

21. Shimazaki, K.; Doi, M.; Assmann, S.M.; Kinoshita, T. Light regulation of stomatal movement. Annu. Rev. Plant Biol. 2007, 58, 219-247. [CrossRef]

22. Lawson, T. Guard cell photosynthesis and stomatal function. New Phytol. 2009, 181, 13-34. [CrossRef] [PubMed]

23. Santelia, D.; Lawson, T. Rethinking guard cell metabolism. Plant Physiol. 2016, 172, 1371-1392. [CrossRef] [PubMed]

24. Kwok, E.Y.; Hanson, M.R. Stromules and dynamic nature of plastid morphology. J. Microsc. 2004, 214, 124-137. [CrossRef] [PubMed]

25. Hanson, M.R.; Conklin, P.L. Stromules, functional extensions of plastids within the plant cell. Curr. Opin. Plant Biol. 2020, 58, 25-32. [CrossRef] [PubMed]

26. Barton, K.A.; Wozny, M.R.; Mathur, N.; Jaipargas, E.A.; Mathur, J. Chloroplast behaviour and interactions with other organelles in Arabidopsis thaliana pavement cells. J. Cell Sci. 2018, 131, jcs202275. [CrossRef] [PubMed]

27. Itoh, R.D.; Ishikawa, H.; Nakajima, K.P.; Moriyama, S.; Fujiwara, M.T. Isolation and analysis of a stromule-overproducing Arabidopsis mutant suggest the role of PARC6 in plastid morphology maintenance in the leaf epidermis. Physiol. Plant. 2018, 162, 479-494. [CrossRef]

28. Pyke, K.A.; Leech, R.M. A genetic analysis of chloroplast division and expansion in Arabidopsis thaliana. Plant Physiol. 1994, 104, 201-207. [CrossRef] [PubMed]

29. Forth, D.; Pyke, K.A. suffulta mutation in tomato reveals a novel method of plastid replication during fruit ripening. J. Exp. Bot. 2006, 57, 1971-1979. [CrossRef] [PubMed]

30. Chen, Y.; Asano, T.; Fujiwara, M.T.; Yoshida, S.; Machida, Y.; Yoshioka, Y. Plant cells without detectable plastids are generated in the crumpled leaf mutant of Arabidopsis thaliana. Plant Cell Physiol. 2009, 50, 956-969. [CrossRef] [PubMed]

31. Fujiwara, M.T.; Yasuzawa, M.; Sasaki, S.; Nakano, T.; Niwa, Y.; Yoshida, S.; Abe, T.; Itoh, R.D. The Arabidopsis minD mutation causes aberrant FtsZ1 ring placement and moderate heterogeneity of chloroplasts in the leaf epidermis. Plant Signal. Behav. 2017, 12, e1343776. [CrossRef] [PubMed] 
32. Fujiwara, M.T.; Yasuzawa, M.; Kojo, K.H.; Niwa, Y.; Abe, T.; Yoshida, S.; Nakano, T.; Itoh, R.D. The Arabidopsis arc5 and arc6 mutations differentially affect plastid morphology in pavement and guard cells in the leaf epidermis. PLoS ONE 2018, 13, e0192380. [CrossRef]

33. Ishikawa, H.; Yasuzawa, M.; Koike, N.; Sanjaya, A.; Moriyama, S.; Nishizawa, A.; Matsuoka, K.; Sasaki, S.; Kazama, Y.; Hayashi, Y.; et al. Arabidopsis PARC6 is critical for plastid morphogenesis in pavement, trichome, and guard cells in leaf epidermis. Front. Plant Sci. 2020, 10, 1-19. [CrossRef]

34. Waters, M.T.; Moylan, E.C.; Langdale, J.A. GLK transcription factors regulate chloroplast development in a cell-autonomous manner. Plant J. 2008, 56, 432-444. [CrossRef]

35. Chiang, Y.-H.; Zubo, Y.O.; Tapken, W.; Kim, H.J.; Lavanway, A.M.; Howard, L.; Pilon, M.; Kieber, J.J.; Schaller, G.E. Functional characterization of the GATA transcription factors GNC and CGA1 reveals their key role in chloroplast development, growth, and division in Arabidopsis. Plant Physiol. 2012, 160, 332-348. [CrossRef]

36. Behringer, C.; Schwechheimer, C. B-GATA transcription factors-Insights into their structure, regulation, and role in plant development. Front. Plant Sci. 2015, 6, 90. [CrossRef]

37. Wu, D.; Wright, D.A.; Wetzel, C.; Voytas, D.F.; Rodermel, S. The IMMUTANS variegation locus of Arabidopsis defines a mitochondrial alternative oxidase homolog that functions during early chloroplast biogenesis. Plant Cell 1999, 11, 43-55. [CrossRef]

38. Aluru, M.; Bae, H.; Wu, D.; Rodermel, S. The Arabidopsis immutans mutation affects plastid differentiation and the morphogenesis of white and green sectors in variegated plants. Plant Physiol. 2001, 127, 67-77. [CrossRef] [PubMed]

39. Negi, J.; Munemasa, S.; Song, B.; Tadakuma, R.; Fujita, M.; Azoulay-Shemer, T.; Engineer, C.B.; Kusumi, K.; Nishida, I.; Schroeder J.I.; et al. Eukaryotic lipid metabolic pathaway is essential for functional chloroplasts and $\mathrm{CO}_{2}$ and light responses in Arabidopsis guard cells. Proc. Natl. Acad. Sci. USA 2018, 115, 9038-9043. [CrossRef]

40. Fan, J.; Zhai, Z.; Yan, C.; Xu, C. Arabidopsis TRIGALACTOSYLDIACYLGLYCEROL5 interacts with TGD1, TGD2, and TGD4 to facilitate lipid transfer from the endoplasmic reticulum to plastids. Plant Cell 2015, 27, 2941-2955. [CrossRef]

41. Itoh, R.D.; Nakajima, K.P.; Sasaki, S.; Ishikawa, H.; Kazama, Y.; Abe, T.; Fujiwara, M.T. TGD5 is required for normal morphogenesis of non-mesophyll plastids, but not mesophyll chloroplasts, in Arabidopsis. Plant J. 2021. [CrossRef] [PubMed]

42. Chen, G.; Bi, Y.R.; Li, N. EGY1 encodes a membrane-associated and ATP-independent metalloprotease that is required for chloroplast development. Plant J. 2005, 41, 364-375. [CrossRef]

43. Li, B.; Li, Q.; Xiong, L.; Kronzucker, H.J.; Krämer, U.; Shi, W. Arabidopsis plastid AMOS1/EGY1 integrates abscisic acid signaling to regulate global gene expression response to ammonium stress. Plant Physiol. 2012, 160, 2040-2051. [CrossRef] [PubMed]

44. Chen, C.; Wang, J.; Zhao, X. Leaf senescence induced by EGY1 defection was partially restored by glucose in Arabidopsis thaliana. Bot. Stud. 2016, 57, 1-9. [CrossRef]

45. Qi, Y.; Wang, X.; Lei, P.; Li, H.; Yan, L.; Zhao, J.; Meng, J.; Shao, J.; An, L.; Yu, F.; et al. The chloroplast metalloproteases VAR2 and EGY1 act synergistically to regulate chloroplast development in Arabidopsis. J. Biol. Chem. 2020, 295, 1036-1046. [CrossRef]

46. Barry, C.S.; Aldridge, G.M.; Herzog, G.; Ma, Q.; McQuinn, R.P.; Hirschberg, J.; Giovannoni, J.J. Altered chloroplast development and delayed fruit ripening caused by mutations in a Zinc metalloprotease at the lutescent2 locus of tomato. Plant Physiol. 2012, 159, 1086-1098. [CrossRef]

47. Zhang, S.; Zhi, H.; Li, W.; Shan, J.; Tang, C.; Jia, G.; Tang, S.; Diao, X. SiYGL2 is involved in the regulation of leaf senescence and photosystem II efficiency in Setaria italica (L.) P. Beauv. Front. Plant Sci. 2018, 9, 1308. [CrossRef] [PubMed]

48. Wu, X.; Gong, D.; Xia, F.; Dai, C.; Zhang, X.; Gao, X.; Wang, S.; Qu, X.; Sun, Y.; Liu, G. A two-step mutation process in the double WS1 homologs drives the evolution of burley tobacco, a special chlorophyll-deficient mutant with abnormal chloroplast development. Planta 2020, 251, 10. [CrossRef] [PubMed]

49. Sanjaya, A.; Kazama, Y.; Ishii, K.; Muramatsu, R.; Kanamaru, K.; Ohbu, S.; Abe, T.; Fujiwara, M.T. An argon-ion-induced pale green mutant of Arabidopsis exhibiting rapid disassembly of mesophyll chloroplast grana. Plants 2021, 10, 848. [CrossRef] [PubMed]

50. Hirano, T.; Kazama, Y.; Ohbu, S.; Shirakawa, Y.; Liu, Y.; Kambara, T.; Fukunishi, N.; Abe, T. Molecular nature of mutations induced by high-LET irradiation with argon and carbon ions in Arabidopsis thaliana. Mutat. Res. 2012, 735, 19-31. [CrossRef]

51. Kazama, Y.; Ohbu, S.; Hayashi, Y.; Abe, T. Identification of heavy-ion-beam induced DNA mutation by genetic mapping in Arabidopsis mutant. RIKEN Accel. Prog. Rep. 2010, 43, 283.

52. Sanjaya, A.; Asano, M.; Fujiwara, M.T.; (Sophia University, Tokyo, Japan); Kazama, Y.; Abe, T.; (RIKEN, Wako, Japan). Personal communication, 2021.

53. Woodson, J.D.; Perez-Ruiz, J.M.; Schmitz, R.J.; Ecker, J.R.; Chory, J. Sigma factor-mediated plastid retrograde signals control nuclear gene expression. Plant J. 2013, 73, 1-13. [CrossRef]

54. Oh, S.; Montgomery, B.L. Phytochrome-induced SIG2 expression contributes to photoregulation of phytochrome signalling and photomorphogenesis in Arabidopsis thaliana. J. Exp. Bot. 2013, 64, 5457-5472. [CrossRef]

55. Rodermel, S. Arabidopsis variegation mutants. In The Arabidopsis Book; American Society of Plant Biologists: Rockville, MD, USA, 2002. [CrossRef]

56. Odell, J.T.; Nagy, F.; Chua, N.-H. Identification of DNA sequences required for activity of the cauliflower mosaic virus 35S promoter. Nature 1985, 313, 810-812. [CrossRef] 
57. Sessions, A.; Weigel, D.; Yanofsky, M.F. The Arabidopsis thaliana MERISTEM LAYER 1 promoter specifies epidermal expression in meristems and young primordia. Plant J. 1999, 20, 259-263. [CrossRef]

58. Efremova, N.; Schreiber, L.; Bär, S.; Heidmann, I.; Huijser, P.; Wellesen, K.; Schwarz-Sommer, Z.; Saedler, H.; Yephremov, A. Functional conservation and maintenance of expression pattern of FIDDLEHEAD-like genes in Arabidopsis and Antirrhinum. Plant Mol. Biol. 2004, 56, 821-837. [CrossRef]

59. Chiu, W.; Niwa, Y.; Zeng, W.; Hirano, T.; Kobayashi, H.; Sheen, J. Engineered GFP as a vital reporter in plants. Curr. Biol. 1996, 6, 325-330. [CrossRef]

60. Fujiwara, M.; Nagashima, A.; Kanamaru, K.; Tanaka, K.; Takahashi, H. Three new nuclear genes, sigD, sigE and sigF encoding putative plastid RNA polymerase sigma factors in Arabidopsis thaliana. FEBS Lett. 2000, 481, 47-52. [CrossRef]

61. Abe, T.; Takahashi, T.; Komeda, Y. Cloning and characterization of an L1 layer-specific gene in Arabidopsis thaliana. Plant Cell Physiol. 1999, 40, 571-580. [CrossRef] [PubMed]

62. Abe, T.; Takahashi, T.; Komeda, Y. Identification of a cis-regulatory element for L1 layer-specific gene expression, which is targeted by an L1-specific homeodomain protein. Plant J. 2001, 26, 487-494. [CrossRef]

63. Clough, S.J.; Bent, A.F. Floral dip: A simplified method for Agrobacterium-mediated transformation of Arabidopsis thaliana. Plant J. 1998, 16, 735-743. [CrossRef] [PubMed]

64. Tanaka, H.; Watanabe, M.; Sasabe, M.; Hiroe, T.; Tanaka, T.; Tsukaya, H.; Ikezaki, M.; Machida, C.; Machida, Y. Novel receptor-like kinase ALE2 controls shoot development by specifying epidermis in Arabidopsis. Development 2007, 134, 1643-1652. [CrossRef] [PubMed]

65. Szakonyi, D.; Byrne, M.E. Ribosomal protein L27a is required for growth and patterning in Arabidopsis thaliana. Plant J. 2011, 65, 269-281. [CrossRef] [PubMed]

66. Barton, M.K.; Poethig, R.S. Formation of the shoot apical meristem in Arabidopsis thaliana: An analysis of development in the wild type and in the shoot meristemless mutant. Development 1993, 119, 823-831. [CrossRef]

67. Martínez-Zapater, J.M. Genetic analysis of variegated mutants in Arabidopsis. J. Hered. 1993, 84, 138-140. [CrossRef]

68. Yamamoto, Y.Y.; Puente, P.; Deng, X.-W. An Arabidopsis cotyledon-specific albino locus: A possible role in 16S rRNA maturation. Plant Cell Physiol. 2000, 41, 68-76. [CrossRef]

69. Albrecht, V.; Ingenfeld, A.; Apel, K. Characterization of the snowy cotyledon 1 mutant of Arabidopsis thaliana: The impact of chloroplast elongation factor $\mathrm{G}$ on chloroplast development and plant vitality. Plant Mol. Biol. 2006, 60, 507-518. [CrossRef]

70. Nadeau, J.A.; Sack, F.D. Stomatal development in Arabidopsis. In The Arabidopsis Book; American Society of Plant Biologists: Rockville, MD, USA, 2002.

71. Donnelly, P.M.; Bonetta, D.; Tsukaya, H.; Dengler, R.E.; Dengler, N.G. Cell cycling and cell enlargement in developing leaves of Arabidopsis. Dev. Biol. 1999, 215, 407-419. [CrossRef] [PubMed]

72. Andriankaja, M.; Dhondt, S.; De Bodt, S.; Vanhaeren, H.; Coppens, F.; De Milde, L.; Mühlenbock, P.; Skirycz, A.; Gonzalez, N.; Beemster, G.T.S.; et al. Exit from proliferation during leaf development in Arabidopsis thaliana: A not-so-gradual process. Dev. Cell 2012, 22, 64-78. [CrossRef] [PubMed]

73. Kusumi, K.; Mizutani, A.; Nishimura, M.; Iba, K. A virescent gene $V_{1}$ determines the expression timing of plastid genes for transcription/translation apparatus during early leaf development in rice. Plant J. 1997, 12, 1241-1250. [CrossRef]

74. Gügel, I.L.; Soll, J. Chloroplast differentiation in the growing leaves of Arabidopsis thaliana. Protoplasma 2017, 254, 1857-1866. [CrossRef]

75. Fujiwara, M.T.; Sanjaya, A.; Itoh, R.D. Arabidopsis thaliana leaf epidermal guard cells: A model for studying chloroplast proliferation and partitioning in plants. Front. Plant Sci. 2019, 10, 1403. [CrossRef] [PubMed]

76. Osteryoung, K.W.; Pyke, K.A. Division and dynamic morphology of plastids. Annu. Rev. Plant Biol. 2014, 65, 443-472. [CrossRef] [PubMed]

77. Pyke, K.; Zubko, M.K.; Day, A. Marking cell layers with spectinomycin provides a new tool for monitoring cell fate during leaf development. J. Exp. Bot. 2000, 51, 1713-1720. [CrossRef]

78. Guo, D.; Gao, X.; Li, H.; Zhang, T.; Chen, G.; Huang, P.; An, L.; Li, N. EGY1 plays a role in regulation of endodermal plastid size and number that are involved in ethylene-dependent gravitropism of light-grown Arabidopsis hypocotyls. Plant Mol. Biol. 2008, 66, 345-360. [CrossRef]

79. Kirk, J.T.O.; Tilney-Bassett, R.A.E. The Plastids. Their Chemistry, Structure, Growth and Inheritance; Elsevier: North Holland, Amsterdam, 1978.

80. Sakamoto, W. Leaf-variegated mutations and their responsible genes in Arabidopsis thaliana. Genes Genet. Syst. 2003, 78, 1-9. [CrossRef] [PubMed]

81. Toshoji, H.; Katsumata, T.; Takusagawa, M.; Yusa, Y.; Sakai, A. Effects of chloroplast dysfunction on mitochondria: White sectors in variegated leaves have higher mitochondrial DNA levels and lower dark respiration rates than green sectors. Protoplasma 2012, 249, 805-817. [CrossRef]

82. Schnurr, J.; Shockey, J.; Browse, J. The acyl-CoA synthetase encoded by LACS2 is essential for normal cuticle development in Arabidopsis. Plant Cell 2004, 16, 629-642. [CrossRef] [PubMed]

83. Ando, E.; Kinoshita, T. Red light-induced phosphorylation of plasma membrane H+-ATPase in stomatal guard cells. Plant Physiol. 2018, 178, 838-849. [CrossRef] 
84. Iwai, S.; Ogata, S.; Yamada, N.; Onjo, M.; Sonoike, K.; Shimazaki, K. Guard cell photosynthesis is crucial in abscisic acid-induced stomatal closure. Plant Direct 2019, 3, e00137. [CrossRef]

85. Brunkard, J.O.; Runkel, A.M.; Zambryski, P.C. Chloroplasts extend themselves independently and in response to internal redox signals. Proc. Natl. Acad. Sci. USA 2015, 112, 10044-10049. [CrossRef]

86. Caplan, J.L.; Kumar, A.S.; Park, E.; Padmanabhan, M.S.; Hoban, K.; Modla, S.; Czymmek, K.; Dinesh-Kumar, S.P. Chloroplast stromules function during innate immunity. Dev. Cell 2015, 34, 45-57. [CrossRef] [PubMed]

87. Jiang, S.-C.; Engle, N.L.; Banday, Z.Z.; Cecchini, N.M.; Jung, H.W.; Tschaplinski, T.J.; Greenberg, J.T. ALD1 accumulation in Arabidopsis epidermal plastids confers local and non-autonomous disease resistance. J. Exp. Bot. 2021, 72, 2710-2726. [CrossRef]

88. Irieda, H.; Takano, Y. Epidermal chloroplasts are defense-related motile organelles equipped with plant immune components Nat. Commun. 2021, 12, 2739. [CrossRef]

89. Winter, D.; Vinegar, B.; Nahal, H.; Ammar, R.; Wilson, G.V.; Provart, N.J. An "Electronic Fluorescent Pictograph" browser for exploring and analyzing large-scale biological data sets. PLoS ONE 2007, 2, e718. [CrossRef] [PubMed]

90. Gunning, B.E.S.; Steer, M.W. Plant Cell Biology: An Ultrastructural Approach; Edward Arnold: London, UK, 1975.

91. McNellis, T.W.; von Arnim, A.G.; Araki, T.; Komeda, Y.; Misera, S.; Deng, X.W. Genetic and molecular analysis of an allelic series of cop 1 mutants suggests functional roles for the multiple protein domains. Plant Cell 1994, 6, 487-500. [CrossRef]

92. Alonso, J.M.; Stepanova, A.N.; Leisse, T.J.; Kim, C.J.; Chen, H.; Shinn, P.; Stevenson, D.K.; Zimmerman, J.; Barajas, P.; Cheuk, R.; et al. Genome-wide insertional mutagenesis of Arabidopsis thaliana. Science 2003, 301, 653-657. [CrossRef] [PubMed]

93. Murashige, T.; Skoog, F. A revised medium for rapid growth and bio assays with tobacco tissue cultures. Physiol. Plant. 1962, 15, 473-497. [CrossRef] 